\title{
Biomarcadores exosomales: nuevas perspectivas para el diagnóstico y pronóstico de las enfermedades respiratorias
}

\section{Exosomal biomarkers: new perspectives for the diagnosis and prognosis of respiratory diseases}

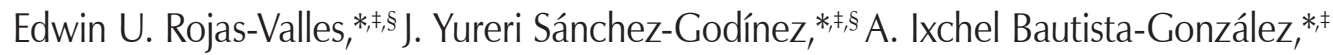 \\ Ana E. Garduño-Torres, ${ }^{* \neq}$ Yolanda González*
}

\footnotetext{
*Instituto Nacional de Enfermedades Respiratorias Ismael Cosío Villegas, Ciudad de México, México; ${ }^{\ddagger}$ Universidad Nacional Autónoma de México, Ciudad de México, México; ${ }^{\S}$ Los autores contribuyeron de igual manera en esta revisión.
}

\begin{abstract}
RESUMEN. Los exosomas son pequeñas vesículas secretadas por las células del hospedero después de la degradación de partículas inertes o de microorganismos. Su tamaño de $<0.1 \mu \mathrm{m}$ les permite migrar del pulmón hacia diferentes órganos, trasportando dentro de su interior microARNs (miARNs), entre otras moléculas. En las enfermedades no infecciosas como el cáncer, asma y fibrosis pulmonar al igual que en las infecciosas como influenza, COVID-19, neumonías y tuberculosis existe una expresión diferencial de miARNs, por lo que se han propuesto como biomarcadores para el diagnóstico y/o como posibles blancos terapéuticos. En las enfermedades infecciosas se ha encontrado tanto material genético del patógeno como miARNs del hospedero, con funciones reguladoras bimodales, es decir, pueden participar tanto promoviendo la infección como controlando la progresión de la enfermedad. Los exosomas pueden controlar las infecciones virales como la influenza y SARS-CoV-2 al bloquear directamente la entrada del virus a las células del hospedero y al expresar el receptor (ácido siálico o ACE2) en la superficie del exosoma, por lo que se sugieren como blancos terapéuticos. Adicionalmente, los miARNs exosomales se han propuesto para nuevas vacunas contra la tuberculosis activa y latente. La mayoría de los biomarcadores aún se encuentran en fase preclínica, por lo que se requieren estudios clínicos para evaluar su eficacia. En esta revisión conjuntaremos el papel de los ARNs exosomales y su función en las enfermedades pulmonares causadas por agentes infecciosos y no infecciosos así como biomarcadores para el diagnóstico y de pronóstico, y su posible uso terapéutico.
\end{abstract}

Palabras clave: Exosomas, enfermedades pulmonares, miARNs, biomarcadores de diagnóstico.

\begin{abstract}
Exosomes are small vesicles secreted by host cells after degradation of inert particles or microorganisms. Their size of $<0.1$ $\mu \mathrm{m}$ allows them to migrate from the lung to different organs, carrying within them micro RNAs (miRNAs) and other host molecules. It has been reported that in non-infectious lung diseases, such as cancer, asthma, and pulmonary fibrosis, as well as in infectious diseases, such as influenza, COVID-19, pneumonia, and tuberculosis, there is a differential expression of miRNAs, and they have been proposed as biomarkers for diagnosis and/ or as possible therapeutic targets. Additionally, in infectious diseases, both pathogen genetic material and host miRNAs have been found in exosomes with bimodal regulatory functions, that is, they may participate either in promoting infection or controlling disease progression. In infection with influenza viruses and SARS-CoV-2, exosomes can directly block entry into host cells by expressing the receptor on their own surface, thus suggesting them as therapeutic targets. Additionally, another function of exosomal miRNAs is as new vaccines for active and latent tuberculosis. Most of the biomarkers are still in the preclinical phase, so clinical studies are required to evaluate their efficacy as biomarkers for the diagnosis of pulmonary diseases. In this review we will focus on the most relevant information on the role of exosomal RNAs and their function in lung diseases caused by infectious and non-infectious agents, as biomarkers for diagnosis and as prognostic biomarkers, and their possible therapeutic use.
\end{abstract}

Keywords: Exosomes, lung diseases, miRNAs, diagnostic biomarkers.

\section{Correspondencia:}

\section{Dra. Yolanda González}

Instituto Nacional de Enfermedades Respiratorias Ismael Cosío Villegas, Ciudad de México, México.

Correo electrónico: ygonzalezh@iner.gob.mx

Trabajo recibido: 1-III-2021; aceptado: 14-VII-2021.

Citar como: Rojas-Valles EU, Sánchez-Godínez JY, Bautista-González Al, Garduño-Torres AE, González Y. Biomarcadores exosomales: nuevas perspectivas para el diagnóstico y pronóstico de las enfermedades respiratorias. Neumol Cir Torax. 2021; 80 (4): 269-285. https://dx.doi.org/10.35366/103452 


\section{INTRODUCCIÓN}

Debido a que el pulmón es una de las principales vías de entrada de partículas y microorganismos patógenos, cuenta con un sistema inmunológico innato de defensa capaz de eliminarlos. Los macrófagos son las células encargadas de llevar a cabo un proceso continuo de eliminación de agentes externos a través de la fagocitosis (internalización de partículas o microorganismos), la degradación y la exocitosis (expulsión de las partículas o microorganismos degradados por medio de vesículas). Los productos de la exocitosis contienen material genético que puede ser indicativo de una patología. Debido a que el diagnóstico del agente patógeno en las enfermedades pulmonares requiere procedimientos invasivos que pueden comprometer la salud de los pacientes, en las últimas décadas se han realizado estudios en muestras biológicas no invasivas como la sangre periférica para identificar biomarcadores asociados a la enfermedad. Los biomarcadores o marcadores biológicos se definen como «una característica que mide y evalúa objetivamente como un indicador de procesos biológicos normales, procesos patológicos o respuestas farmacológicas a una intervención terapéutica». ${ }^{1}$ Aunque existe una gran cantidad de biomarcadores, las vesículas extracelulares de menor tamaño son de gran relevancia diagnóstica debido a que pueden migrar desde el órgano que los originó hacia la periferia, donde ejercen su función y pueden detectarse.

Los exosomas son microvesículas extracelulares de 30 a $100 \mathrm{~nm}$ de diámetro, derivadas de los cuerpos multivesiculares que se forman después de la ingestión de patógenos o partículas que se digieren dentro de los macrófagos y posteriormente son liberadas por exocitosis. ${ }^{2-4}$ Los exosomas pueden transportar moléculas tanto de la célula de origen como del patógeno, entre las que se encuentran: péptidos, proteínas, ARN mensajero (mARN) funcional y con mayor frecuencia, pequeños fragmentos de ARN conocidos como microARN (miARN). ${ }^{5}$

En esta revisión nos enfocaremos en conjuntar la información más relevante de los ARNs exosomales y su función en las enfermedades pulmonares causadas por agentes infecciosos y no infecciosos, enfocados en la comprensión de la enfermedad como biomarcadores para el diagnóstico o de pronóstico, y su posible uso terapéutico.

\section{BIOMARCADORES EXOSOMALES EN LAS ENFERMEDADES PULMONARES CAUSADAS POR AGENTES NO INFECCIOSOS}

ASMA

En México 8.5 millones de personas padecen asma, la cual es una afección respiratoria caracterizada por inflamación crónica ${ }^{6}$ en la que se produce una obstrucción respiratoria provocada por broncoconstricción, formación de edema así como una respuesta $\mathrm{T}_{\mathrm{H}} 2$ y secreción de IgE. Esta inflamación ocurre en respuesta a diversos estímulos tales como alérgenos, infecciones y contaminantes del aire. ${ }^{7-9}$ Durante la crisis asmática, los linfocitos T CD4+ reconocen los alérgenos ambientales y se diferencian en linfocitos $\mathrm{T}_{\mathrm{H}} 2$, los cuales producen citocinas como las interleucinas: IL-4, IL-5 e IL-13; además, también inducen la proliferación y la activación de las células cebadas y eosinófilos, lo que incrementa el proceso alérgico. ${ }^{8,10}$

En respuesta a los alérgenos, las células cebadas, los eosinófilos, las células dendríticas y las células epiteliales bronquiales generan exosomas, y el contenido intraexosomal incluye metabolitos activos y miARNs que regulan la activación o supresión de la respuesta inmunitaria y/o inducen la tolerancia inmunológica (Tabla 1).,10-18 Estas moléculas y miARNs se han propuesto como biomarcadores de diagnóstico y como blancos terapéuticos para el control del asma. ${ }^{710-18}$

En los últimos años se ha profundizado el estudio de los exosomas para comprender el papel que tienen en los mecanismos fisiológicos y patológicos del asma. De manera general, se observó que las proteínas y algunos metabolitos están asociados con la patogenia de la enfermedad, mientras que los miARNs están asociados con la regulación y protección (Tabla 1).

\section{EPOC}

La enfermedad pulmonar obstructiva crónica (EPOC) es la tercera causa de defunción a nivel global; ${ }^{19}$ en México se reportaron 29,000 defunciones atribuibles a la EPOC en 2017. ${ }^{20}$ La EPOC es una enfermedad caracterizada por la inflamación crónica de las vías respiratorias que se produce por la inhalación de partículas o gases nocivos, y que limita el flujo del aire en los pulmones..$^{21,22}$ Se ha identificado un amplio grupo de factores genéticos y ambientales como las causas del inicio y la progresión de la EPOC, siendo el tabaquismo una de las principales. ${ }^{21} \mathrm{Su}$ patología se caracteriza por la destrucción de la estructura alveolar, la remodelación y el estrechamiento de las vías respiratorias pequeñas inducidas por inhalación de gases y partículas contaminantes..$^{23,24}$

Aunque el papel de los exosomas en la EPOC ha sido poco estudiado, se ha reportado un incremento de los exosomas circulantes en pacientes con EPOC y durante la exacerbación aguda. ${ }^{25} \mathrm{El}$ aumento en la producción de exosomas se correlaciona con marcadores inflamatorios sistémicos como el factor de necrosis tumoral (TNF) soluble y la IL-6, sugiriendo la relación entre los exosomas y el proceso inflamatorio en la EPOC. ${ }^{25}$ Por otro lado, en modelos de ratones se ha descrito que el mecanismo por el cual los exosomas contribuyen al desarrollo de la EPOC es a través 
Tabla 1: Metabolitos y miARNs en asma.

\begin{tabular}{|c|c|c|c|c|c|}
\hline Metabolito & Origen & Modelo & Efecto & Uso & Referencia \\
\hline $\begin{array}{l}\text { LTA4 hidrolasa y } \\
\text { LTC4 sintasa }\end{array}$ & \begin{tabular}{|c|} 
Células dendríticas \\
derivadas de monocitos
\end{tabular} & $\begin{array}{l}\text { In vitro, células } \\
\text { dendríticas y } \\
\text { macrófagos }\end{array}$ & $\begin{array}{l}\text { Pueden metabolizar LTA4 a LT } \\
\text { proinflamatorio B4 y C4, que } \\
\text { inducen la migración de PMN }\end{array}$ & Objetivo terapéutico & $7,10,14$ \\
\hline $\begin{array}{l}\text { TGF- } \beta 1, \text { IL-4 y } \\
\text { GM-CSF }\end{array}$ & Células dendríticas & $\begin{array}{l}\text { In vitro, células } \\
\text { dendríticas }\end{array}$ & $\begin{array}{l}\text { Modifican el fenotipo de las } \\
\text { CPA, modulan la expresión y } \\
\text { actividad de las enzimas de la } \\
\text { vía LT en CPA }\end{array}$ & $\begin{array}{c}\text { Diagnóstico y comprensión de } \\
\text { la enfermedad }\end{array}$ & 7,14 \\
\hline ETA y LTB4 & Células dendríticas & $\begin{array}{l}\text { Modelos in vitro de } \\
\text { células dendríticas }\end{array}$ & $\begin{array}{c}\text { Quimiotácticos para } \\
\text { eosinófilos y neutrófilos, } \\
\text { inducen la migración de } \\
\text { PMN y el reclutamiento } \\
\text { de granulocitos a sitios } \\
\text { inflamatorios }\end{array}$ & $\begin{array}{l}\text { Comprensión de la } \\
\text { enfermedad }\end{array}$ & $7,10,11$ \\
\hline TGF- $\beta 1$ & Macrófagos & In vitro, macrófagos & $\begin{array}{c}\text { Disminuye la formación de } \\
\text { exosomas }\end{array}$ & Objetivo terapéutico & 10,11 \\
\hline $\begin{array}{c}\text { Guanosina } \\
\text { trifosfato } \\
\text { fosfatasas de Rab }\end{array}$ & Macrófagos & In vitro, macrófagos & $\begin{array}{l}\text { Reguladores del tráfico } \\
\text { de membranas, están } \\
\text { involucrados en el mecanismo } \\
\text { de liberación de exosomas }\end{array}$ & Objetivo terapéutico & 11 \\
\hline IL-1及 & Macrófagos & In vitro, macrófagos & $\begin{array}{l}\text { Induce la diseminación } \\
\text { microvesicular de los } \\
\text { monocitos de sangre } \\
\text { periférica }\end{array}$ & Objetivo terapéutico & 11 \\
\hline IFN- $\gamma$ & $\begin{array}{l}\text { Líquido de lavado } \\
\text { broncoalveolar }\end{array}$ & Modelo de ratones & $\begin{array}{c}\text { Incrementa la secreción de } \\
\text { exosomas en macrófagos } \\
\text { alveolares }\end{array}$ & Objetivo terapéutico & 11 \\
\hline POE, PBM y PCE & $\begin{array}{l}\text { Exosomas de } \\
\text { eosinófilos }\end{array}$ & Humano & $\begin{array}{l}\text { Tienen funciones autócrinas } \\
\text { y parácrinas, y mejoran la } \\
\text { migración de eosinófilos } \\
\text { e inducen la expresión de } \\
\text { moléculas de adhesión como } \\
\text { ICAM-1 y la integrina } \alpha 2\end{array}$ & $\begin{array}{l}\text { Comprensión de la } \\
\text { enfermedad }\end{array}$ & 10,11 \\
\hline Bet v1 & Células B & Humanos & $\begin{array}{l}\text { Induce una respuesta de } \\
\text { citocinas } \mathrm{T}_{\mathrm{H}} 2 \text {, caracterizada por } \\
\text { la liberación de IL-4, IL-5 e IL-13, } \\
\text { y niveles bajos de IFN- } \gamma \text { y TNF- } \alpha\end{array}$ & Objetivo terapéutico & 11,17 \\
\hline $\lg \mathrm{E}$ & Células cebadas & Humano & $\begin{array}{l}\text { Induce la estimulación y la } \\
\text { proliferación de linfocitos, e } \\
\text { incrementa la producción de } \\
\text { IL-2, IL-12, IFN- } \gamma \text {, IL-6 e IL-8. }\end{array}$ & Objetivo terapéutico & $10,11,12$ \\
\hline CD63 y OX40L & $\begin{array}{c}\text { Células cebadas } \\
\text { derivadas de la médula } \\
\text { ósea }\end{array}$ & Modelo de ratón & $\begin{array}{c}\text { Se ligan con } 0 X 40 \text { en la } \\
\text { superficie de las células Te } \\
\text { inducen la proliferación de } \\
\text { células T y la diferenciación } \\
\text { de las células } \mathrm{T}_{\mathrm{H}} 2\end{array}$ & Objetivo terapéutico & 10,18 \\
\hline Fc\&RI & Células cebadas & Humano & $\begin{array}{c}\text { Se une a lgE libre, } \\
\text { disminuyendo los niveles } \\
\text { séricos de lgE, y limita los } \\
\text { efectos de la activación de las } \\
\text { células cebadas }\end{array}$ & Objetivo terapéutico & 10 \\
\hline
\end{tabular}




\begin{tabular}{|c|c|c|c|c|c|c|}
\hline \multicolumn{7}{|c|}{ Continúa Tabla 1: Metabolitos y miARNs en asma. } \\
\hline \multirow{2}{*}{$\begin{array}{c}\text { Metabolito } \\
\text { miARNs }\end{array}$} & \multirow[t]{2}{*}{ Origen } & \multirow[t]{2}{*}{ Modelo } & \multirow[t]{2}{*}{ Efecto } & \multicolumn{2}{|c|}{ Uso } & \multirow[t]{2}{*}{ Referencia } \\
\hline & & & & & & \\
\hline miR-150 & $\begin{array}{c}\text { Células T citotóxicas } \\
\text { CD8 + }\end{array}$ & Modelo de ratón & $\begin{array}{l}\text { Suprime la dermatitis } \\
\text { alérgica de contacto e induce } \\
\text { tolerancia de antígenos } \\
\text { específicos en ratones }\end{array}$ & $\begin{array}{c}\text { Biomarcador } \\
\text { diagnóstico } \\
\text { y objetivos } \\
\text { terapéuticos }\end{array}$ & $\begin{array}{l}\text { Disminución } \\
\text { de la } \\
\text { expresión }\end{array}$ & 10,16 \\
\hline miR-221 & $\begin{array}{l}\text { Células del músculo } \\
\text { liso/tejido pulmonar }\end{array}$ & $\begin{array}{l}\text { Humano/modelo de } \\
\text { ratón }\end{array}$ & $\begin{array}{l}\text { Regulación de la proliferación } \\
\text { celular }\end{array}$ & $\begin{array}{l}\text { Biomarcador } \\
\text { diagnóstico }\end{array}$ & $\begin{array}{l}\text { Incremento } \\
\text { en la } \\
\text { expresión }\end{array}$ & 11 \\
\hline miR-21 & Suero & Humano & $\begin{array}{l}\text { Regulación de la expresión de } \\
\text { citocinas como la IL-12 }\end{array}$ & $\begin{array}{l}\text { Biomarcador } \\
\text { diagnóstico }\end{array}$ & $\begin{array}{l}\text { Incremento } \\
\text { en la } \\
\text { expresión }\end{array}$ & 11 \\
\hline miR-346 & Tejidos pulmonares & Modelo de ratón & $\begin{array}{c}\text { Disminuye la respuesta } \mathrm{T}_{\mathrm{H}} 2 \text {, } \\
\text { regulando la expresión de IL-5 } \\
\text { e IL-13 }\end{array}$ & $\begin{array}{l}\text { Biomarcador } \\
\text { diagnóstico } \\
\text { y objetivos } \\
\text { terapéuticos }\end{array}$ & $\begin{array}{l}\text { Disminución } \\
\text { de la } \\
\text { expresión }\end{array}$ & 7,15 \\
\hline miR-1827 & Tejidos pulmonares & Modelo de ratón & $\begin{array}{c}\text { Disminuye la respuesta } \mathrm{T}_{\mathrm{H}}^{2} \text {, } \\
\text { regulando la expresión de IL-5 } \\
\text { e IL-13 }\end{array}$ & $\begin{array}{c}\text { Biomarcador } \\
\text { diagnóstico } \\
\text { y objetivos } \\
\text { terapéuticos }\end{array}$ & $\begin{array}{l}\text { Disminución } \\
\text { de la } \\
\text { expresión }\end{array}$ & 7,15 \\
\hline miR-574-5p & Tejidos pulmonares & Modelo de ratón & $\begin{array}{c}\text { Disminuye la respuesta } \mathrm{T}_{H} 2 \text {, } \\
\text { regulando la expresión de IL-5 } \\
\text { e IL-13 }\end{array}$ & $\begin{array}{l}\text { Biomarcador } \\
\text { diagnóstico } \\
\text { y objetivos } \\
\text { terapéuticos }\end{array}$ & $\begin{array}{l}\text { Disminución } \\
\text { de la } \\
\text { expresión }\end{array}$ & 7,15 \\
\hline miR-let-7 & Tejidos pulmonares & Modelo de ratón/CD4+ & $\begin{array}{c}\text { Regula la secreción de IL-13 } \\
\text { en células T }\end{array}$ & $\begin{array}{c}\text { Biomarcador } \\
\text { diagnóstico } \\
\text { y objetivos } \\
\text { terapéuticos }\end{array}$ & $\begin{array}{l}\text { Disminución } \\
\text { de la } \\
\text { expresión }\end{array}$ & 11,13 \\
\hline miR-15a & Esputo y suero & Células T CD4+ & $\begin{array}{c}\text { Regulación de la } \\
\text { angiogénesis y la migración } \\
\text { celular }\end{array}$ & $\begin{array}{l}\text { Biomarcador } \\
\text { diagnóstico }\end{array}$ & $\begin{array}{c}\text { Disminución } \\
\text { de la } \\
\text { expresión }\end{array}$ & 11 \\
\hline $\begin{array}{c}\text { miR-146a y miR- } \\
146 b\end{array}$ & $\begin{array}{l}\text { Células del músculo } \\
\text { liso humanas }\end{array}$ & Humano & $\begin{array}{l}\text { Regulación la expresión } \\
\text { e inflamación de } \\
\text { ciclooxigenasa-2 e IL-1 } 1 \beta\end{array}$ & $\begin{array}{l}\text { Biomarcador } \\
\text { diagnóstico }\end{array}$ & $\begin{array}{l}\text { Disminución } \\
\text { de la } \\
\text { expresión }\end{array}$ & 11 \\
\hline miR-19a & Esputo y suero & Humano & $\begin{array}{l}\text { Regulación de la expresión de } \\
\text { SOCS1 y A20 }\end{array}$ & $\begin{array}{l}\text { Biomarcador } \\
\text { diagnóstico }\end{array}$ & $\begin{array}{l}\text { Incremento } \\
\text { en la } \\
\text { expresión }\end{array}$ & 11 \\
\hline miR-126 & Tejido pulmonar & Modelo de ratón & Regulación de la inflamación & $\begin{array}{l}\text { Biomarcador } \\
\text { diagnóstico y } \\
\text { pronóstico }\end{array}$ & $\begin{array}{l}\text { Incremento } \\
\text { en la } \\
\text { expresión }\end{array}$ & 11 \\
\hline
\end{tabular}

LTA4H hidrolasa = leucotrieno A4 hidrolasa, LTC4 sintasa = leucotrieno C4 sintasa, TGF- $\beta 1=$ factor de crecimiento transformador de citocinas reguladoras beta $1, \mathrm{IL}=$ interleucinas, GM-CSF = factor estimulante de colonias de granulocitos y macrófagos, LT = leucotrieno, CPA = células presentadoras de antígeno, ETA = ácido 5-cetoeicosatetraenoico, LTB4 = leucotrieno B4, PMN = leucocitos polimorfonucleares, IFN- $\gamma=$ interferón-gamma, TNF- $\alpha=$ factor de necrosis tumoral, POE $=$ peroxidasa de eosinófilos, PBM = proteína básica de mielina, PCE = proteína catiónica de eosinófilos, SOCS1 = supresor de la señalización de citosinas, Bet v1 = péptido de abedul, ICAM.1 = molécula de adhesión intercelular 1 .

de la elastasa transportada dentro de los exosomas, la cual une y degrada la matriz extracelular (MEC). ${ }^{26}$

En muestras de resección y de células pulmonares se han identificado miARNs exosomales, los cuales pueden ser útiles como biomarcadores para el diagnóstico y como objetivos terapéuticos, ${ }^{21,27-36}$ (Tabla 2). Aún se requiere buscar su expresión en los exosomas del suero de los pacientes para ser más accesible su uso diagnóstico. 
Tabla 2: miARNs en la enfermedad pulmonar obstructiva crónica (EPOC).

\begin{tabular}{|c|c|c|c|c|c|c|}
\hline miARN & Muestra & Modelo & Expresión & Efecto & Uso & Referencia \\
\hline \multicolumn{7}{|l|}{ EV-exosomas } \\
\hline miR-210 & $\begin{array}{l}\text { Neumonectomía y } \\
\text { lobectomía }\end{array}$ & Humano & $\begin{array}{l}\text { Incremento en la } \\
\text { expresión }\end{array}$ & $\begin{array}{c}\text { Regula la autofagia } \\
\text { a través de ATG7 en } \\
\text { fibroblastos pulmonares }\end{array}$ & Objetivo terapéutico & 32 \\
\hline \multicolumn{7}{|l|}{$\begin{array}{l}\text { Células } \\
\text { pulmonares }\end{array}$} \\
\hline miR-181c & $\begin{array}{l}\text { Resección } \\
\text { pulmonar }\end{array}$ & $\begin{array}{c}\text { Humano/modelo en } \\
\text { ratones }\end{array}$ & $\begin{array}{l}\text { Disminución en la } \\
\text { expresión }\end{array}$ & $\begin{array}{l}\text { Regula la respuesta } \\
\text { inflamatoria, } \\
\text { quimiotaxis de } \\
\text { neutrófilos, generación } \\
\text { de especies reactivas } \\
\text { de oxígeno }\end{array}$ & Objetivo terapéutico & 29 \\
\hline miR-126 & Sangre/in vivo & $\begin{array}{l}\text { Humano/modelo } \\
\text { murino }\end{array}$ & $\begin{array}{l}\text { Disminución en la } \\
\text { expresión }\end{array}$ & $\begin{array}{c}\text { Función en la } \\
\text { angiogénesis y la } \\
\text { homeostasis vascular }\end{array}$ & Objetivo terapéutico & 30 \\
\hline miR-145 & $\begin{array}{l}\text { Las células } \\
\text { primarias del } \\
\text { músculo liso de los } \\
\text { pulmones }\end{array}$ & Humano & $\begin{array}{l}\text { Incremento en la } \\
\text { expresión }\end{array}$ & $\begin{array}{l}\text { Regula la liberación } \\
\text { de citocinas } \\
\text { proinflamatorias (IL-6 y } \\
\text { CXCL8) en las células } \\
\text { del músculo liso por } \\
\text { medio de la molécula } \\
\text { SMAD3 }\end{array}$ & $\begin{array}{l}\text { Objetivo terapéutico } \\
\text { y biomarcador } \\
\text { diagnóstico }\end{array}$ & 31 \\
\hline miR-29c & Sangre & Humano & $\begin{array}{l}\text { Incremento en la } \\
\text { expresión }\end{array}$ & $\begin{array}{l}\text { Es un regulador } \\
\text { negativo de la } \\
\text { expresión de la } \\
\text { colágena }\end{array}$ & $\begin{array}{l}\text { Diagnóstico, } \\
\text { estadificación y } \\
\text { pronóstico de la } \\
\text { enfermedad }\end{array}$ & 33,35 \\
\hline miR-126 & Sangre & Humano & $\begin{array}{l}\text { Disminución en la } \\
\text { expresión }\end{array}$ & $\begin{array}{l}\text { Regula la producción } \\
\text { de CXCL12 }\end{array}$ & $\begin{array}{l}\text { Diagnóstico, } \\
\text { estadificación y } \\
\text { pronóstico de la } \\
\text { enfermedad }\end{array}$ & 33,36 \\
\hline miR-146a & Esputo & Humano & $\begin{array}{l}\text { Disminución en la } \\
\text { expresión }\end{array}$ & $\begin{array}{l}\text { Induce la expresión } \\
\text { de COX-2 y PGE2 }\end{array}$ & $\begin{array}{l}\text { Diagnóstico, } \\
\text { estadificación y } \\
\text { pronóstico de la } \\
\text { enfermedad }\end{array}$ & 27,34 \\
\hline miR-let- 7c & Esputo & Humano & $\begin{array}{l}\text { Disminución en la } \\
\text { expresión }\end{array}$ & $\begin{array}{c}\text { Su expresión } \\
\text { correlaciona } \\
\text { inversamente con } \\
\text { la concentración del } \\
\text { TNF-RII }\end{array}$ & $\begin{array}{l}\text { Diagnóstico, } \\
\text { estadificación y } \\
\text { pronóstico de la } \\
\text { enfermedad }\end{array}$ & 27,34 \\
\hline miR-34a & $\begin{array}{c}\text { Células } \\
\text { microvasculares de } \\
\text { pulmón }\end{array}$ & Humano & $\begin{array}{l}\text { Incremento en la } \\
\text { expresión }\end{array}$ & $\begin{array}{l}\text { Controla la expresión de } \\
\text { AKT, y la proteína p53 }\end{array}$ & $\begin{array}{l}\text { Biomarcador } \\
\text { diagnóstico }\end{array}$ & 28,34 \\
\hline miR-199a-5p & $\begin{array}{l}\text { Células } \\
\text { microvasculares de } \\
\text { pulmón }\end{array}$ & Humano & $\begin{array}{l}\text { Incremento en la } \\
\text { expresión }\end{array}$ & $\begin{array}{c}\text { Su expresión } \\
\text { correlaciona } \\
\text { inversamente con } \\
\text { la expresión de la } \\
\text { proteína HIF-1 } \alpha\end{array}$ & $\begin{array}{l}\text { Biomarcador } \\
\text { diagnóstico }\end{array}$ & 28,34 \\
\hline
\end{tabular}

$\mathrm{IL}=$ interleucinas, $\mathrm{CXCL} 8$ = por sus siglas en inglés C-X-C motif Chemiokine Ligand 8, SMAD3 = por sus siglas en inglés mothers against decapentaplegic homolog 3, CXCL-12 $=$ por sus siglas en inglés C-X-C motif chemokine ligand 12, COX-2 = ciclooxigenasa-2, PGE2 = prostaglandina E2, RTFN-II = receptor del factor de necrosis tumoral tipo II. 
Tabla 3: miARNs en la fibrosis pulmonar.

\begin{tabular}{|c|c|c|c|c|c|c|}
\hline miARN & Muestra & Modelo & Expresión & Efecto & Uso & Referencia \\
\hline miR-142-3p & Esputo & Humano & $\begin{array}{l}\text { Disminución en } \\
\text { la expresión }\end{array}$ & $\begin{array}{c}\text { Induce la } \\
\text { proliferación de } \\
\text { progenitores } \\
\text { mesenquimales } \\
\text { mediante el control } \\
\text { de la señalización } \\
\text { de WNT }\end{array}$ & $\begin{array}{l}\text { Biomarcador } \\
\text { diagnóstico }\end{array}$ & 41 \\
\hline miR-let-7d-5p & Esputo & Humano & $\begin{array}{l}\text { Disminución en } \\
\text { la expresión }\end{array}$ & $\begin{array}{l}\text { Induce la transición } \\
\text { mesenquimal } \\
\text { epitelial en las } \\
\text { células epiteliales } \\
\text { pulmonares }\end{array}$ & $\begin{array}{l}\text { Biomarcador } \\
\text { diagnóstico }\end{array}$ & 41 \\
\hline miR-21 & Tejido pulmonar & Modelo murino & $\begin{array}{l}\text { Incremento en } \\
\text { la expresión }\end{array}$ & $\begin{array}{c}\text { Reprime Smad7 } \\
\text { promoviendo } \\
\text { la activación } \\
\text { de fibroblastos } \\
\text { mediada por TGF- } \beta\end{array}$ & $\begin{array}{c}\text { Biomarcador } \\
\text { diagnóstico } \\
\text { y objetivo } \\
\text { terapéutico }\end{array}$ & $38,46,50$ \\
\hline miR-200 & Pulmones & Modelo murino & $\begin{array}{l}\text { Disminución en } \\
\text { la expresión }\end{array}$ & $\begin{array}{l}\text { Inhibe la TEM } \\
\text { inducida por } \\
\text { TGF- } \beta \text { en células } \\
\text { epiteliales } \\
\text { alveolares mediante } \\
\text { la represión de } \\
\text { los factores de } \\
\text { transcripción } \\
\text { GATA3, ZEB1 o } \\
\text { ZEB2 }\end{array}$ & $\begin{array}{l}\text { Objetivo } \\
\text { terapéutico }\end{array}$ & 38,47 \\
\hline miR-30 & $\begin{array}{c}\text { Células } \\
\text { pulmonares }\end{array}$ & Humano & $\begin{array}{l}\text { Disminución en } \\
\text { la expresión }\end{array}$ & $\begin{array}{l}\text { Inhibe la expresión } \\
\text { de Smad3 }\end{array}$ & $\begin{array}{l}\text { Objetivo } \\
\text { terapéutico }\end{array}$ & 39,50 \\
\hline miR-99 & $\begin{array}{c}\text { Células } \\
\text { pulmonares/ } \\
\text { tejido pulmonar }\end{array}$ & $\begin{array}{l}\text { Humano/modelo } \\
\text { murino }\end{array}$ & $\begin{array}{l}\text { Disminución en } \\
\text { la expresión }\end{array}$ & $\begin{array}{c}\text { Activa la } \\
\text { señalización de } \\
\text { TGF- } \beta \text {, regula la } \\
\text { expresión de CAV1 } \\
\text { (mediador crítico } \\
\text { del proceso de } \\
\text { fibrosis pulmonar) } \\
\text { y participa en los } \\
\text { procesos fibróticos }\end{array}$ & $\begin{array}{l}\text { Objetivo } \\
\text { terapéutico }\end{array}$ & 39,43 \\
\hline miR-let-7 & $\begin{array}{c}\text { Células } \\
\text { pulmonares/ } \\
\text { tejido pulmonar }\end{array}$ & $\begin{array}{l}\text { Humano/modelo } \\
\text { murino }\end{array}$ & $\begin{array}{l}\text { Disminución en } \\
\text { la expresión }\end{array}$ & $\begin{array}{l}\text { Se asocia con el } \\
\text { proceso fibrótico }\end{array}$ & $\begin{array}{l}\text { Objetivo } \\
\text { terapéutico }\end{array}$ & $13,44,39$ \\
\hline miR-22 & Tejido pulmonar & Modelo murino & $\begin{array}{l}\text { Incremento en } \\
\text { la expresión }\end{array}$ & $\begin{array}{l}\text { Induce la vía de } \\
\text { señalización ERK } \\
\text { en fibroblastos } \\
\text { pulmonares } \\
\text { humanos mediante la } \\
\text { regulación de CTGF }\end{array}$ & $\begin{array}{l}\text { Objetivo } \\
\text { terapéutico }\end{array}$ & $38,44,45$ \\
\hline
\end{tabular}

WNT = Acrónimo del gen wingless de Drosophila y de su homólogo en vertebrados integrated o Int -1, TGF- $\beta=$ factor de crecimiento transformante $\beta$, TEM, $\beta$-lactamasas TEM, GATA3 = , ZEB1 = factor transcripcional ZEB1, ZEB2 = factor transcripcional ZEB2, CAV1 = Caveolina 1, ERK = Extracellular signal-regulated kinase, CTGF = factor de crecimiento de tejido conectivo. 
Tabla 4: miARNs en cáncer pulmonar.

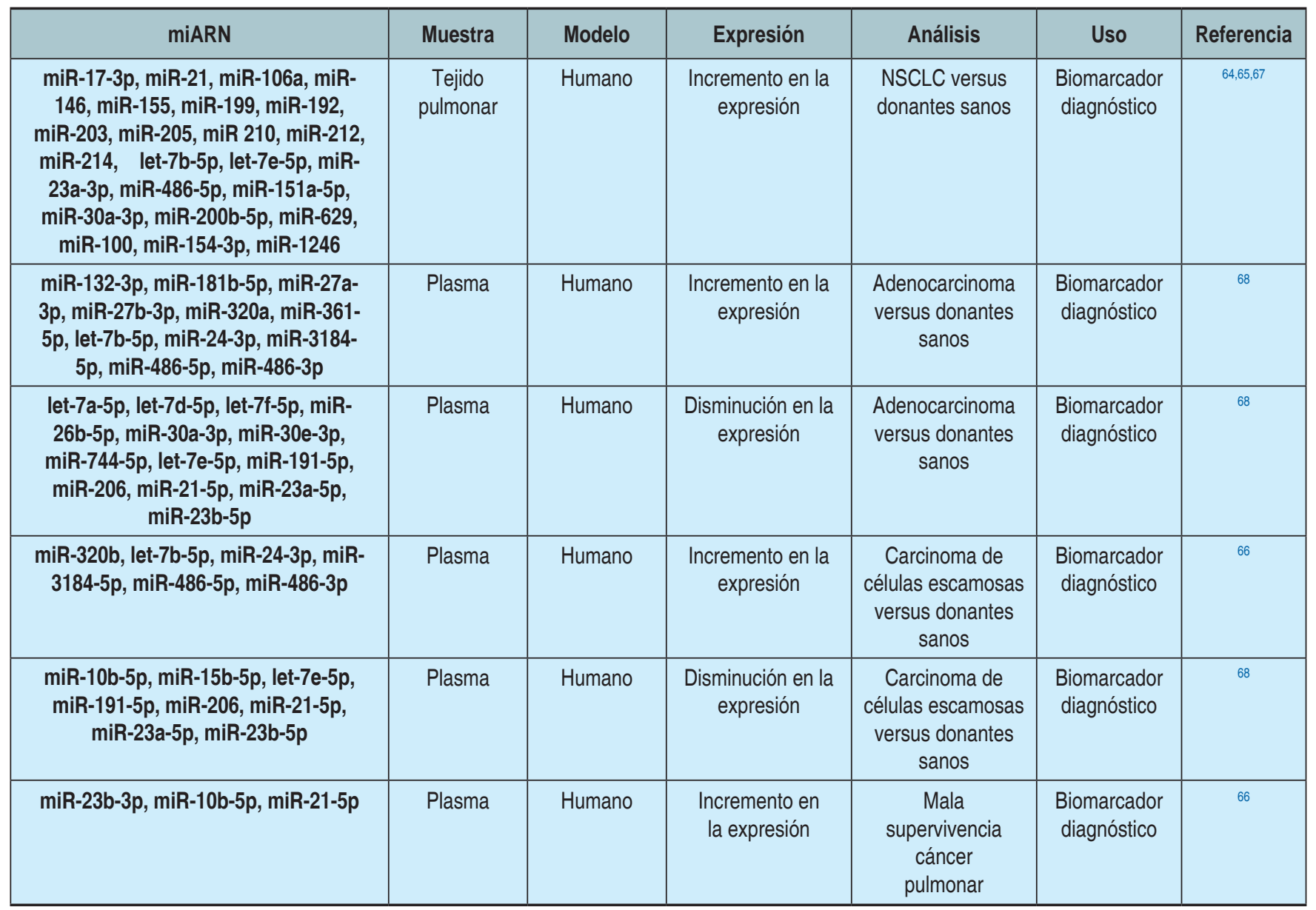

NSCLC = cáncer pulmonar de células no pequeñas.

\section{Fibrosis pulmonar}

No se cuenta con datos epidemiológicos de la fibrosis pulmonar idiopática (FPI) en nuestro país; se estima que en promedio cada neumólogo de México diagnostica ocho pacientes con FPI por año. ${ }^{37}$ Actualmente, la pirfenidona y el nintedanib son las únicas opciones de tratamiento aprobadas por la Administración de Medicamentos y Alimentos de los Estados Unidos (FDA), pero no detienen ni revierten la fibrosis, sino que simplemente retardan la progresión de la enfermedad. Al ser una enfermedad progresiva, incurable y mortal es de suma importancia su estudio con el fin de encontrar marcadores tempranos de la enfermedad o alternativas terapéuticas. ${ }^{39}$ La FPI es una enfermedad pulmonar intersticial fibrosante progresiva e irreversible de etiología desconocida que conduce a la muerte. ${ }^{39}$ En la FPI se observa formación de focos fibroblásticos y el depósito excesivo de proteínas de la MEC. ${ }^{38}$ Se caracteriza por un proceso de cicatrización anormal del tejido pulmonar que produce un exceso de tejido fibrótico; a medida que la fibrosis se engrosa, el tejido pulmonar va perdiendo la capacidad de facilitar el intercambio de gases y llevar el oxígeno a la sangre. ${ }^{39,40}$

Los exosomas y su contenido tienen un especial interés como objetivos terapéuticos y como biomarcadores diagnósticos en la FPI. Se han identificado miARNs involucrados en el desarrollo de fibrosis de órganos; ${ }^{38}$ en pacientes con FPI se han observado cambios significativos en la expresión de miARNs, como miR-21, miR-200 y Let-7, entre otros. Recientemente se informó que la disminución de la expresión de miR-30a podría estar asociada con la progresión de la FPI. Los estudios de los miARNs provenientes de muestras como el esputo, el tejido y células del pulmón se describen en la Tabla 3. ${ }^{36,41-50}$ Actualmente, la FPI se estudia de manera activa debido a la falta de tratamientos eficaces. Se ha puesto mayor interés en los miARNs, ya que pueden ser útiles como biomarcadores diagnósticos así como posibles objetivos terapéuticos, aunque sería de gran utilidad diagnóstica identificar esos miARNs en exosomas séricos. 


\section{Cáncer pulmonar}

Anualmente se diagnostican aproximadamente 6,000,000 de casos nuevos de cáncer de pulmón (CP) a nivel global. ${ }^{43,51}$ En México se diagnostican 9,000 casos nuevos de $\mathrm{CP}$, siendo la primera causa de muerte por cáncer. ${ }^{52} \mathrm{El} \mathrm{CP}$ es un crecimiento anormal y descontrolado de células que invaden y destruyen el tejido pulmonar. ${ }^{53,54}$ Este tipo de CP se divide en células pequeñas, que tienen una incidencia de $25 \%$, y en células no pequeñas que contienen dos subtipos patológicos principales: adenocarcinoma y carcinoma de células escamosas, con una incidencia de $80 \%{ }^{55,56}$ El CP es de mal pronóstico y la supervivencia es de cinco años. ${ }^{57}$

Los exosomas han sido ampliamente estudiados en cáncer, y se sabe que contribuyen a la progresión tumoral acarreando oncogenes, ${ }^{58}$ regulando la modulación del sistema inmunológico, ${ }^{59}$ que propicia el crecimiento tumoral ${ }^{60}$ y la formación de nichos premetastásicos, ${ }^{61}$ entre otros. ${ }^{62,63}$ Esto conduce a una red de interacciones muy complejas.
Los exosomas en cáncer tienen un papel bimodal, es decir, pueden modificar el entorno local y/o sistémico y contribuir al desarrollo y esparcimiento del cáncer ${ }^{4}$ o pueden activar al sistema inmunológico para inducir una respuesta antitumoral. ${ }^{57}$ En la Tabla 4 se muestran los miARNs identificados en plasma y en tejido pulmonar y sus utilidades clínicas. Aún se requiere identificar una procedencia exosomal que sugiera una asociación directa con el cáncer pulmonar.

\section{BIOMARCADORES EXOSOMALES EN LAS ENFERMEDADES PULMONARES CAUSADAS POR MICROORGANISMOS PATÓGENOS}

\section{Influenza}

Se estima que cada año entre 3,000,000 y 5,000,000 de personas se enferman gravemente por influenza y entre 290,000 y 650,000 personas fallecen a causa de la influenza a nivel global. ${ }^{69}$ La influenza es una infección viral que

Tabla 5: miARNs en tuberculosis pulmonar.

\begin{tabular}{|c|c|c|c|c|c|c|}
\hline $\begin{array}{l}\text { hsa-let-7e-5p y } \\
\text { hsa-let-7d-5p }\end{array}$ & Suero sanguíneo & Humano & $\begin{array}{c}\text { Incremento en la } \\
\text { expresión }\end{array}$ & $\begin{array}{l}\text { En la respuesta inmunológica hacia } M . \\
\text { tuberculosis }\end{array}$ & $\begin{array}{c}\text { Biomarcador } \\
\text { diagnóstico para } \\
\text { TBL }\end{array}$ & $119,120,125,126$ \\
\hline hsa-miR-142-3p & Suero sanguíneo & Humano & $\begin{array}{c}\text { Incremento en la } \\
\text { expresión }\end{array}$ & $\begin{array}{l}\text { Modula la fagocitosis interactuando con } \\
\mathrm{N} \text {-Wasp en las células hospedero }\end{array}$ & $\begin{array}{l}\text { Biomarcador } \\
\text { diagnóstico }\end{array}$ & 119,127 \\
\hline miR-23a-5p & Suero sanguíneo & Humano & $\begin{array}{c}\text { Incremento en la } \\
\text { expresión }\end{array}$ & $\begin{array}{l}\text { Induce la autofagia y la supervivencia de } M \text {. } \\
\text { tuberculosis }\end{array}$ & $\begin{array}{l}\text { Biomarcador } \\
\text { diagnóstico }\end{array}$ & 119,129 \\
\hline miR-484 & Sangre periférica & Humano & $\begin{array}{c}\text { Incremento en la } \\
\text { expresión }\end{array}$ & $\begin{array}{l}\text { Regula las vías metabólicas activando la } \\
\text { proteína de fisión mitocondrial } 1\end{array}$ & $\begin{array}{l}\text { Biomarcador } \\
\text { diagnóstico }\end{array}$ & $121,130,131$ \\
\hline miR-6848 & Sangre periférica & Humano & $\begin{array}{c}\text { Incremento en la } \\
\text { expresión }\end{array}$ & $\begin{array}{c}\text { Induce la expresión de mirtrones para facilitar } \\
\text { la infección por M. tuberculosis }\end{array}$ & $\begin{array}{l}\text { Biomarcador } \\
\text { diagnóstico }\end{array}$ & 130 \\
\hline miR-6849 & Sangre periférica & Humano & $\begin{array}{c}\text { Incremento en la } \\
\text { expresión }\end{array}$ & $\begin{array}{c}\text { Induce la expresión de mirtrones para facilitar } \\
\text { la infección por M. tuberculosis }\end{array}$ & $\begin{array}{l}\text { Biomarcador } \\
\text { diagnóstico }\end{array}$ & 130 \\
\hline miR-20b & $\begin{array}{l}\text { Exosomas de } \\
\text { plasma }\end{array}$ & Humano & $\begin{array}{c}\text { Incremento en la } \\
\text { expresión }\end{array}$ & \begin{tabular}{|c|} 
Regula el factor de transcripción HIF1 y \\
regula genes involucrados en la proliferación \\
celular, migración, metabolismo energético, \\
angiogénesis y apoptosis
\end{tabular} & $\begin{array}{l}\text { Biomarcador } \\
\text { diagnóstico }\end{array}$ & 122,123 \\
\hline
\end{tabular}

NWASP-proteína = neural del síndrome de Wiskott-Aldrich, BCG = vacuna de Bacillus Calmette-Guerin, ATC4a = Autophagy Related 4a Cysteine Peptidase, RAW264.7 $=$ línea celular de macrófagos de ratones, HIF-1 = factor 1 inducible por hipoxia. 

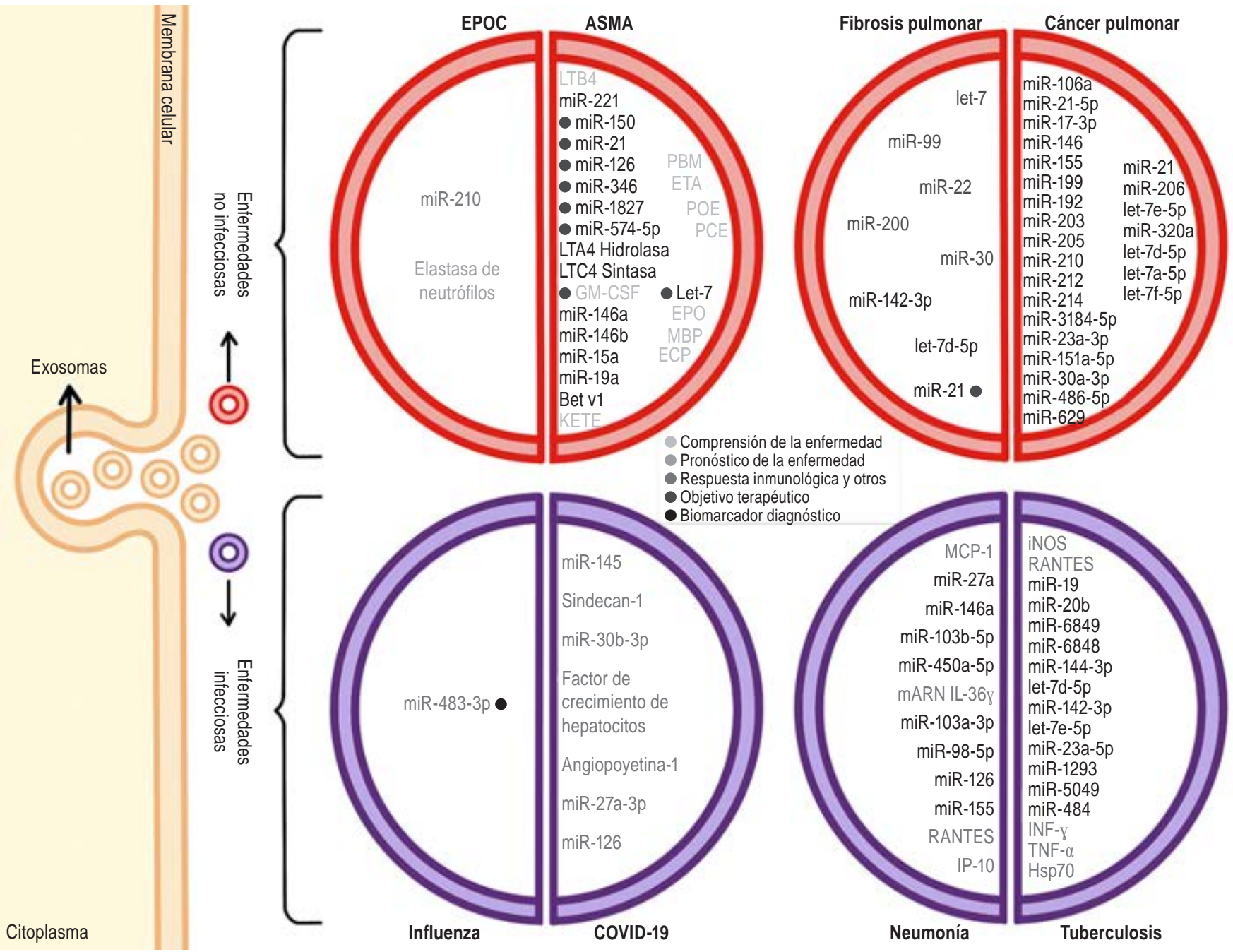

Figura 1: Contenidos exosomales que se inducen en las enfermedades pulmonares. miRNAs exosomales que se han identificado en las enfermedades no infecciosas como EPOC, asma, fibrosis y cáncer pulmonar (círculos rojos) y las enfermedades infecciosas como influenza, COVID-19, neumonía y tuberculosis (círculos morados), y que se han sugerido como pronóstico de la enfermedad, en la respuesta inmunitaria y como objetivos terapéuticos o biomarcadores para el diagnóstico. EPOC = enfermedad pulmonar obstructiva crónica, GM-CSF = factor estimulante de colonias de granulocitos y macrófagos, PBM = proteína básica de mielina, ETA = ácido 5-cetoeicosatetraenoico, $\mathrm{POE}=$ peroxidasa de eosinófilos, $\mathrm{PCE}=$ proteína catiónica de eosinófilos, $\mathrm{EPO}=$ eritropoyetina, $\mathrm{MBP}=$ major basic protein o principal proteína básica, $\mathrm{KETE}=5$-keto eicosatetraenoic acid o ácido 5-ceto eicosatetranoico, TNF- $\alpha=$ factor de necrosis tumoral, $\mathrm{Hsp} 70=$ beat shock protein, proteína de shock térmico de $70 \mathrm{KDa}$.

afecta la nariz, la garganta, los bronquios y los pulmones; se transmite mediante gotículas y pequeñas partículas expulsadas con la tos y/o los estornudos, y puede producir desde una enfermedad tipo gripal con síntomas leves hasta neumonías e incluso la muerte. Existen cuatro tipos de virus de influenza: A-D; sin embargo, los que representan un problema de salud pública son los virus de influenza $A$ (IAV, por sus siglas en inglés) y $B$, siendo el IAV el causante de la epidemia de influenza en 2009 en México. ${ }^{70}$

El virus de influenza A (IAV) es parte de la familia Orthomyxoviridae, está compuesto por ocho segmentos de ARN monocatenario encerrados dentro de una matriz proteica. ${ }^{71}$ Algunas de las proteínas que codifican los segmentos de ARN son NS2, NS1, M1, M2, NP, PB1, PB2, PA, y HA, que es una proteína de unión al receptor, y NA, enzima que degrada ácido siálico, entre otras. En la infección por el IAV, la proteína HA se une a receptores celulares con residuos de ácido siálico, permitiendo la entrada del virus. ${ }^{72} \mathrm{El} \mathrm{IAV}$ se clasifica en subtipos de acuerdo con las combinaciones de dos proteínas de superficie: la hemaglutinina (HA), y la neuraminidasa (NA). Actualmente hay dos subtipos que circulan entre humanos: AH1N1 y AH3N2.

Los exosomas derivados de células infectadas con IAV pueden activar las células del sistema inmunológico a través de los epítopos virales de la HA H-2M cargados en las moléculas del complejo principal de histocompatibilidad clase 
II (MHCII), los cuales pueden ser presentados a las células $\mathrm{T}$ e inducir una respuesta inmunitaria en el hospedero. ${ }^{73}$ También se ha observado que los exosomas pueden unir las partículas virales por reconocimiento del ácido siálico, neutralizando la capacidad infectiva de los virus. ${ }^{74}$

Los miARNs contenidos en los exosomas tienen funciones reguladoras; se ha identificado que el miR-483-3p aislado de lavado broncoalveolar durante la infección por el IAV, inhibe los reguladores negativos de la vía de señalización RIG-I e induce la expresión de citocinas proinflamatorias y genes estimulados por IFN (interferón), como IL-6, CCL2, TNF- $\alpha$ y SP110. En influenza aviar, el miR-483-3p de exosomas regula la producción de citocinas inflamatorias como el IFN- $\beta$, IL-6, CCL2 y TNF- $\alpha$ en células endoteliales vasculares, sugiriendo que podría ser un mecanismo por el que se produce una secreción exacerbada de citocinas proinflamatorias. ${ }^{75}$ Ambos miARNs podrían ser biomarcadores para el desarrollo de la inflamación excesiva en pacientes con influenza.

Al igual que en la EPOC, en la influenza se han reportado miARNs provenientes de tejidos y células pulmonares como posibles biomarcadores, por lo que su identificación en los exosomas séricos proporcionaría un uso más generalizado. Se ha identificado la expresión del miR-146a asociada a la replicación de IAV, mientras que la disminución en la expresión reprime la replicación viral; el mecanismo sugerido es a través de la disminución de la respuesta de los interferones tipo 1. Al inhibir el miR-146a, se observó que las lesiones pulmonares (LP) de ratones disminuyen y la tasa de supervivencia se incrementa, sugiriendo que el miR-146a podría ser un blanco terapéutico para disminuir la severidad de la infección por IAV. ${ }^{76}$ Otros miARNs de importancia clínica son el miR302c que, al igual que el miR-146a, propicia la replicación viral a través de la disminución de la expresión IFN- $\beta{ }^{77}$ y los miARNs: hsa-mir-127-3p, hsa-mir-486-5p, hsa-mir-593-5p y mmu-mir-487b-5p, los cuales en un tratamiento combinado suprimieron la replicación viral y mejoraron eficazmente la protección contra una dosis letal de IAV en ratones. ${ }^{78}$

Debido a la capacidad de los miARNs para neutralizar las partículas virales y su participación en la inducción de moléculas antivirales como los IFN-I, los miARNs podrían ser blancos terapéuticos en las infecciones causadas por IAV.

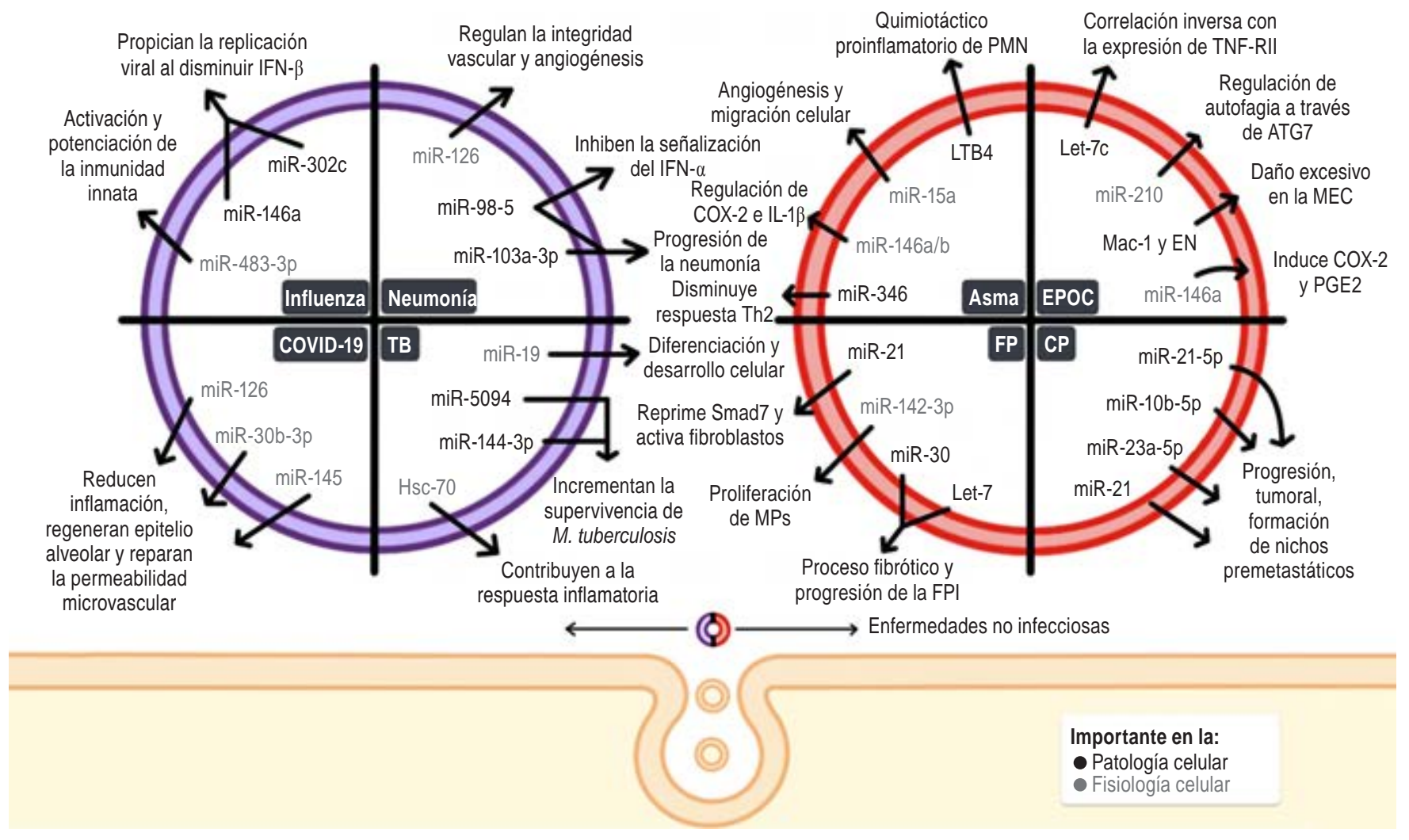

Figura 2: Exosomas y su papel en las enfermedades pulmonares. Efecto de los miARNs en la fisiología y patología de las enfermedades pulmonares no infecciosas (círculo morado). Efecto de los miARNs en la fisiología y patología de las enfermedades pulmonares infecciosas (círculo rojo).

TB = tuberculosis, $\mathrm{FPI}=$ fibrosis pulmonar idiopática, $\mathrm{MPs}=$ micropartículas, $\mathrm{PMN}=$ polimorfonucleares, $\mathrm{TNF}=$ por sus siglas en inglés, tumor necrosis factor, ATG7 $=$ autophagy related 7 protein, $\mathrm{MEC}=$ matriz extracelular, $\mathrm{COX}-2=$ ciclooxigenasa $-2, \mathrm{PGE} 2=$ prostaglandina E2, EPOC $=$ enfermedad pulmonar obstructivo crónica, $\mathrm{FP}=$ fibrosis pulmonar, $\mathrm{CP}=$ cáncer pulmonar, $\mathrm{MPs}=$ micropartículas. 


\section{COVID-19}

A finales de 2019, un coronavirus previamente desconocido, designado como SARS-CoV-2 y descubierto en la ciudad de Wuhan, China, provocó un brote de neumonía viral inusual denominada COVID-19..$^{79,80}$ La COVID-19 es una enfermedad zoonótica que causa un síndrome respiratorio agudo que se ha extendido por todo el mundo, alcanzando proporciones pandémicas. ${ }^{81}$ Esta enfermedad tiene un espectro clínico muy variable, se presenta tanto como una enfermedad asintomática como con cuadros clínicos paucisintomáticos, leves, moderados, graves o críticos. En el caso de las condiciones clínicas leves se presenta comúnmente fiebre, tos seca, fatiga, dolor de cabeza y neumonía leve; mientras que la condición clínica grave se asocia con disnea, síndrome de dificultad respiratoria aguda (SDRA) e hipoxemia. ${ }^{82}$ Los casos más críticos requieren ventilación mecánica para controlar la insuficiencia respiratoria. En pacientes críticos, las manifestaciones sistémicas como el choque séptico, la disfunción multiorgánica o la insuficiencia multiorgánica a menudo se producen como consecuencia de la tormenta de citocinas inflamatorias desencadenada por el virus. ${ }^{83}$

El SARS-CoV-2 es un $\beta$-coronavirus de cadena positiva sencilla de $A R N,{ }^{84}$ el cual está constituido por la glicoproteína de envoltura pequeña (E), glicoproteína de membrana $(\mathrm{M})$, proteína de nucleocápside $(\mathrm{N})$, varias proteínas accesorias y por la glicoproteína spike (S), que facilita la entrada viral a las células del hospedero mediante el receptor de la enzima convertidora de angiotensina 2 (ACE2, por sus siglas en inglés). La serina proteasa TMPRSS2 interviene en la internalización de la proteína S, fusionándola con la membrana del hospedero. ${ }^{85}$ La relación de los exosomas con la infección por SARS-CoV-2 aún no se ha comprendido completamente; sin embargo, se ha demostrado que la respuesta de las células inmunes es regulada por los exosomas de las células infectadas por virus, aumentando la propagación y la infección del virus a través de la trasmisión del genoma viral a células sanas, además se ha reportado que los receptores exosomales pueden aumentar la entrada del virus a las células, y se piensa que en el caso del SARS-CoV-2, los exosomas pueden estar implicados en la propagación y la infección por los receptores CD9 y ACE2. ${ }^{86}$ Debido a que los virus SARS «secuestran» la maquinaria de biogénesis de las vesículas extracelulares, modificándola para crear un entorno apto para la infección viral, la generación de vesículas con partículas virales podría ser una estrategia para evadir su detección por parte del sistema inmunológico; sin embargo, no se han realizado estudios en profundidad sobre las vesículas extracelulares (EV) y su relación con los coronavirus. ${ }^{87}$

Mediante un análisis computacional se ha reportado que los miARNs del hospedero y los del virus pueden estimular la patogénesis viral a través de la desregulación de algunas de las principales vías de señalización inmune antiviral, como la autofagia y la señalización IFN-I, y también puede aumentar las complicaciones en los pacientes infectados. ${ }^{88,89}$ Se ha sugerido que miR-1207-5p es capaz de interactuar con el genoma de SARS-CoV-2, alterando la regulación del factor estimulante de colonias-1 (CSF-1), lo que propicia una respuesta inflamatoria en pacientes con COVID-19; es probable que esto sea un factor del desarrollo de la FPI debido a la estimulación de la transición epitelial a mesénquima..$^{90}$ Por otro lado, se ha observado que la sobreexpresión de miR-200c inhibe la expresión de ACE2 en cardiomiocitos, lo que podría prevenir complicaciones cardiovasculares. ${ }^{91}$ Además, se ha reportado que las terapias basadas en EV podrían tener un potencial significativo para tratar LP ocasionadas por COVID-19 debido a su capacidad para reducir la inflamación, regenerar el epitelio alveolar, reparar la permeabilidad microvascular así como prevenir la FPI. Estas capacidades son mediadas por los miRs-126, 30b-3p, 145, 27a-3p, sindecan-1, factor de crecimiento de hepatocitos y angiopoyetina-1, los cuales son liberados de las $\mathrm{EV}^{92}$ y posiblemente sean transportadas por exosomas, por lo que se requiere identificarlos en exosomas séricos.

La información sobre el papel de los miARNs en la COVID-19 aún es escasa; sin embargo, los datos reportados están enfocados en su posible uso como biomarcadores y agentes terapéuticos.

\section{Neumonía}

La muerte por neumonía en niños a nivel mundial fue de 808,694 en 2017, lo que corresponde a $15 \%$ de todas las defunciones de niños menores de cinco años. ${ }^{93}$ En México se reportaron 117,731 casos nuevos de neumonía en 2018. ${ }^{94}$ La neumonía es una infección respiratoria aguda causada por una variedad de patógenos, siendo las más frecuentes las infecciones causadas por bacterias como Streptococcus pneumoniae, Haemophilus influenzae y Moraxella catarrhalis; mientras que las infecciones causadas por virus se deben principalmente al virus sincitial respiratorio (VSR). ${ }^{95,96}$ Los patógenos se acumulan en las vías respiratorias inferiores y los alvéolos provocando la entrada de líquido exudativo inflamatorio, ${ }^{97}$ lo que causa infiltrados pulmonares visibles en la radiografía de tórax. ${ }^{97,98}$ La neumonía es un factor de riesgo en individuos muy jóvenes o ancianos, siendo la principal causa individual de mortalidad infantil en todo el mundo. ${ }^{93,95}$

El papel de los exosomas se ha reportado en la infección por S. pneumoniae y Klebsiella pneumoniae, donde se observó que los macrófagos alveolares de ratones y de humanos generan exosomas que contienen miARN que regula la IL-36 $\gamma .{ }^{99}$ También durante la infección con VSR 
se observó transporte de ARN y proteínas del hospedero así como ARN viral, los cuales pueden activar la respuesta inmunitaria innata e inducir la liberación de mediadores proinflamatorios como las quimiocinas MCP-1, IP-10 y RANTES en monocitos humanos y células epiteliales de las vías respiratorias..$^{100}$

Por otro lado, el papel de los exosomas como posibles biomarcadores se ha sugerido como grupos de miARNs. En la neumonía grave adquirida en la comunidad se encontró que la expresión de un subconjunto de miARNs exosomales (miR-146a, miR-27a, miR-126 y miR-155) se incrementa en los exosomas del suero de pacientes con el síndrome de dificultad respiratoria aguda (SDRA). ${ }^{101}$ El miR-126 es de especial importancia, ya que regula la integridad vascular y la angiogénesis al mejorar las acciones del factor del crecimiento endotelial promoviendo la regeneración vascular, ${ }^{102-104}$ por lo que los autores postulan que el miR-126 es inducido en gran parte por una respuesta inflamatoria, lo que explica los niveles elevados del miR-126 en pacientes con SDRA, respaldando su posible uso como biomarcador dirigido para la detección temprana y el pronóstico de SDRA. ${ }^{101}$ También se ha reportado el uso de exosomas y miARNs como posible biomarcador para el diagnóstico de neumonía en niños causada por adenovirus. ${ }^{105}$ El estudio se realizó en suero de niños con neumonía causada por el virus, encontrando la expresión de dos pares de miARNs (miR-450a-5p/miR-103a-3p y miR-103b-5p/miR-98-5p), los cuales pueden proporcionar biomarcadores para el diagnóstico de la enfermedad. ${ }^{105}$ El miR-450a-5p controla la expresión del mARN del STAT 1; el miR-98-5p puede inhibir la activación de la señalización del IFN- $\alpha$ y el miR-103a-3p participa en la diferenciación de linfocitos $\mathrm{T}$, como $\mathrm{T}_{\mathrm{H}} 2$ y $T_{H} 17$, en el asma equino grave. ${ }^{106-108}$ Estos miARNs regulan la vía de señalización de los interferones tipo 1, y pueden afectar la respuesta inmunitaria durante la progresión de la neumonía causada por adenovirus, por lo que se sugieren como posibles biomarcadores. ${ }^{105}$

Debido a que la neumonía es causada por diversos agentes patógenos, se desconoce el papel que tienen los exosomas inducidos por cada microorganismo en esta enfermedad. Los estudios realizados se han enfocado principalmente en la biomedicina para el uso de miARNs como biomarcadores en el diagnóstico de la enfermedad. Debido a la escasa investigación en esta área, se deben realizar más estudios respecto a los exosomas y su contenido molecular para contribuir a la comprensión de la patogenia, diagnóstico y tratamiento de la enfermedad.

\section{Tuberculosis}

De acuerdo con datos de la Organización Mundial de la Salud (OMS), en 2018 se registraron 10,000,000 de perso- nas con tuberculosis (TB) y 1.4 millones murieron a causa de esta enfermedad. La TB es una de las 10 principales causas de defunción y la principal causa de muerte por un solo agente infeccioso a nivel global. ${ }^{109}$ En México se reportaron 1,800 defunciones por TB en 2018, de las cuales 90\% fueron por TB pulmonar..$^{110}$ La TB es una enfermedad infecto-contagiosa causada por Mycobacterium tuberculosis. ${ }^{111}$ La TB puede presentarse como un espectro dinámico desde una infección asintomática hasta una enfermedad potencialmente mortal. ${ }^{112}$ Los bacilos de M. tuberculosis se transmiten por aerosoles y, aunque en 90\% de los individuos infectados causa una infección asintomática, M. tuberculosis es capaz de evadir la respuesta inmunitaria y permanecer en estado latente. ${ }^{113}$ Por otro lado, M. tuberculosis es un bacilo de difícil tratamiento y continuamente se están seleccionando cepas resistentes a los fármacos, generando TB farmacorresistente, lo que aumenta el reto para el control de la enfermedad, ${ }^{112,114}$ por lo que la búsqueda de biomarcadores para el diagnóstico y seguimiento de tratamiento es una de los principales metas.

Existe evidencia de que los exosomas pueden transportar componentes derivados de $M$. tuberculosis después de la infección. ${ }^{115,116}$ Se sabe que los exosomas derivados de macrófagos infectados aumentan la liberación de IFN- $\gamma$, TNF- $\alpha$, RANTES e iNOS; estas citocinas y quimiocinas tienen la capacidad de estimular macrófagos naïve de una manera proinflamatoria y pueden activar células T CD4+ y CD8+, dependiendo de una ruta alternativa de presentación de antígenos a estas células. ${ }^{115,117}$ Además, se ha demostrado que la proteína de choque térmico 70 del huésped transportada en exosomas incrementa la respuesta proinflamatoria. ${ }^{117}$ Por otro lado, los exosomas provenientes de células infectadas por M. tuberculosis contienen un conjunto de miARNs específicos, los cuales son de importancia biomédica, ya que pueden tener un uso como biomarcadores para el diagnóstico de la enfermedad, e incluso diagnosticar entre TB activa y TB latente. Los principales miARNs, su origen, función y uso se muestran en al Tabla 5.118-131

Por último, se ha reportado que los exosomas generados durante la estimulación de macrófagos con proteínas de filtrado de cultivo (PFC) de M. tuberculosis activan las células T y reducen la carga bacteriana en ratones tratados con estos exosomas, similar a los ratones vacunados con bacilo de Calmette-Guérin (BCG); sin embargo, no está claro si esta respuesta se debe a un componente específico en los exosomas o a las proteínas micobacterianas como ESAT-6 (Rv3875), el complejo Ag85 (Rv3804c, Rv1886c, y Rv0129c), MPT64 (1980c), y MPT63 (1926c) acarreadas dentro de los exosomas, las cuales son altamente inmunogénicas. ${ }^{119}$ Por este motivo se han propuesto los exosomas de macrófagos infectados en el diseño de nuevas vacunas; sin embargo, se necesitan más estudios para comprender mejor el mecanismo de acción. ${ }^{132}$ 
Los miARNs y ARNs exosomales expresados o desregulados en las enfermedades pulmonares causadas por agentes infecciosos y no infecciosos para la comprensión de la enfermedad, o para su uso como biomarcadores en el diagnóstico y el pronóstico, y para su uso terapéutico se resumen en la Figura 1.

\section{COMENTARIOS FINALES}

1. El diagnóstico de las enfermedades pulmonares es un desafío debido a que se requiere de procedimientos invasivos para identificar al agente causal, por lo cual, desde hace ya algunas décadas las investigaciones se han enfocado en evaluar los exosomas para su uso clínico. La diferencia de evaluar los miARNs en exosomas, y no la muestra de sangre completa, plasma o suero, es que aumenta la sensibilidad para detectar las secuencias que provienen del sitio de la enfermedad.

2. Los miARNs exosomales diferencialmente expresados en las enfermedades pulmonares se han propuesto como biomarcadores en el diagnóstico, para monitorear las terapias, e incluso como posibles mecanismos para inmunizar. Aunque aún falta por identificar los miARNs que se expresan de manera diferencial en las enfermedades pulmonares como los casos del miR-21 que incrementa su expresión tanto en asma como en fibrosis, del miR-let-7 que disminuye su expresión en asma y fibrosis, del let-7e-5p que incrementó su expresión tanto en tuberculosis como en cáncer y del miR-126 que incrementa su expresión en neumonía y asma, es posible que estos miARNs estén asociados al proceso inflamatorio y no sean específicos de la enfermedad.

3. Los miARNs exosomales que participan en la patología y fisiología de las enfermedades respiratorias se presentan en la Figura 2. Si bien los resultados son prometedores, aún es de gran importancia realizar la investigación de la fase clínica para su uso.

\section{Agradecimientos}

Al Dr. Luis Horacio Gutiérrez González por la revisión crítica y discusión del manuscrito.

\section{REFERENCIAS}

1. Biomarkers Definitions Working Group. Biomarkers and surrogate endpoints: Preferred definitions and conceptual framework. Clin Pharmacol Ther. 2001;69(3):89-95. doi: 10.1067/ mcp.2001.113989.

2. Sandfeld-Paulsen B, Aggerholm-Pedersen N, Baek R, Jakobsen KR, Meldgaard $\mathrm{P}$, Folkersen $\mathrm{BH}$, et al. Exosomal proteins as prognostic biomarkers in non-small cell lung cancer. Mol Oncol. 2016;10(10):1595. doi: 10.1016/j.molonc.2016.10.003.
3. Frydrychowicz M, Kolecka-Bednarczyk A, Madejczyk M, Yasar S, Dworacki G. Exosomes-structure, biogenesis and biological role in non-small-cell lung cancer. Scand J Immunol. 2015;81(1):2-10. doi: 10.1111/sji.12247.

4. Admyre C, Johansson SM, Qazi KR, Filén JJ, Lahesmaa R, Norman $\mathrm{M}$, et al. Exosomes with immune modulatory features are present in human breast milk. J Immunol. 2007;179(3):1969-1978. doi: 10.4049/ jimmunol.179.3.1969.

5. Valadi H, Ekstrom K, Bossios A, Sjostrand M, Lee JJ, Lotvall JO. Exosome-mediated transfer of mRNAs and microRNAs is a novel mechanism of genetic exchange between cells. Nat Cell Biol. 2007;9(6):654-659. doi: 10.1038/ncb1596.

6. Organización Mundial de la Salud. Asma. Published May 20, 2020. [Accesado 14 Febrero 2021] Disponible en: https://www.who.int/es/ news-room/fact-sheets/detail/asthma

7. Huang F, Jia H, Zou Y, Yao Y, Deng Z. Exosomes: an important messenger in the asthma inflammatory microenvironment. J Int Med Res. 2020;48(2):300060520903220. doi: 10.1177/0300060520903220.

8. Fujita Y, Yoshioka Y, Ito S, Araya J, Kuwano K, Ochiya T. Intercellular communication by extracellular vesicles and their MicroRNAs in asthma. Clin Ther. 2014;36(6):873-881. doi: 10.1016/j. clinthera.2014.05.006.

9. Clínica Universidad de Navarra. Diccionario médico. Publicado 2020. [Accesado 14 Febrero 2021] Disponible en: https://www.cun. es/diccionario-medico

10. Mortaz E, Alipoor SD, Varahram M, Jamaati H, Garssen J, Mumby SE, et al. Exosomes in severe asthma: update in their roles and potential in therapy. Biomed Res Int. 2018;2018. doi: $10.1155 / 2018 / 2862187$.

11. Sastre B, Cañas JA, Rodrigo-Muñoz JM, del Pozo V. Novel modulators of asthma and allergy: exosomes and microRNAs. Front Immunol. 2017;8:1. doi: 10.3389/fimmu.2017.00826.

12. Hernández AS. Células colaboradoras (TH1, TH2, TH17) y reguladoras (Treg, TH3, NKT) en la artritis reumatoide. Reumatol Clin Supl. 2009;5(Suppl. 1):1-5. doi: 10.1016/j.reuma.2008.11.012.

13. Kumar M, Ahmad T, Sharma A, Mabalirajan U, Kulshreshtha A, Agrawal $A$, et al. Let-7 microRNA-mediated regulation of IL-13 and allergic airway inflammation. J Allergy Clin Immunol. 2011;128(5):10771085. doi: 10.1016/j.jaci.2011.04.034.

14. Esser J, Gehrmann U, D’Alexandri FL, Hidalgo-Estévez AM, Wheelock $\mathrm{CE}$, Scheynius $A$, et al. Exosomes from human macrophages and dendritic cells contain enzymes for leukotriene biosynthesis and promote granulocyte migration. J Allergy Clin Immunol. 2010;126(5):1032-1040.e4. doi: 10.1016/j.jaci.2010.06.039.

15. Gon Y, Maruoka S, Inoue T, Kuroda K, Yamagishi K, Kozu Y, et al. Selective release of miRNAs via extracellular vesicles is associated with house-dust mite allergen-induced airway inflammation. Clin Exp Allergy. 2017;47(12):1586-1598. doi: 10.1111/cea.13016.

16. Pua HH, Ansel KM, Galli SJ, Vercelli D. MicroRNA regulation of allergic inflammation and asthma. Curr Opin Immunol. 2015;36:101-108. doi: 10.1016/j.coi.2015.07.006.

17. Admyre C, Bohle B, Johansson SM, Focke-Tejkl M, Valenta R, Scheynius A, et al. B cell-derived exosomes can present allergen peptides and activate allergen-specific $T$ cells to proliferate and produce TH2-like cytokines. J Allergy Clin Immunol. 2007;120(6):14181424. doi: 10.1016/j.jaci.2007.06.040.

18. Li F, Wang Y, Lin L, Wang J, Xiao H, Li J, et al. Mast cell-derived exosomes promote Th2 cell differentiation via OX40L-OX40 ligation. J Immunol Res. 2016;2016. doi: 10.1155/2016/3623898. 
19. World Health Organization. The top 10 causes of death. Published 2020. [Accessed February 14, 2021]. Disponible en: https://www.who. int/news-room/fact-sheets/detail/the-top-10-causes-of-death

20. Vázquez-García JC, Hernández-Zenteno R de J, Pérez-Padilla JR, Cano-Salas MC, Fernández-Vega M, Salas-Hernández J, et al. Guía de Práctica Clínica Mexicana para el diagnóstico y tratamiento de la Enfermedad Pulmonar Obstructiva Crónica. Guía Mexicana de EPOC, 2020. Neumol Cir Torax. 2019;78(S1):4-76. doi: 10.35366/nts191a.

21. Salimian J, Mirzaei H, Moridikia A, Harchegani AB, Sahebkar A, Salehi $H$. Chronic obstructive pulmonary disease: MicroRNAs and exosomes as new diagnostic and therapeutic biomarkers. J Res Med Sci. 2018;23:27. doi: 10.4103/jrms.JRMS_1054_17.

22. Barnes PJ, Burney PGJ, Silverman EK, Celli BR, Vestbo J, Wedzicha $\mathrm{JA}$, et al. Chronic obstructive pulmonary disease. Nat Rev Dis Primers. 2015;1:15076. doi: 10.1038/nrdp.2015.76.

23. Kadota T, Fujita Y, Yoshioka Y, Araya J, Kuwano K, Ochiya T. Extracellular vesicles in chronic obstructive pulmonary disease. Int J Mol Sci. 2016;17(11):1801. doi: 10.3390/ijms17111801.

24. Alipoor SD, Mortaz E, Garssen J, Movassaghi M, Mirsaeidi M, Adcock IM. Exosomes and exosomal miRNA in respiratory diseases. Mediators Inflamm. 2016;2016:5628404. doi: 10.1155/2016/5628404.

25. Tan DBA, Armitage J, Teo TH, Ong NE, Shin H, Moodley YP. Elevated levels of circulating exosome in COPD patients are associated with systemic inflammation. Respir Med. 2017;132:261-264. doi: 10.1016/j. rmed.2017.04.014.

26. Genschmer KR, Russell DW, Lal C, Szul T, Bratcher TE, Noerager BD, et al. Activated PMN exosomes: pathogenic entities causing matrix destruction and disease in the lung. Cell. 2019;176(1-2):113-126.e15. doi: 10.1016/j.cell.2018.12.002.

27. Monge ZAC, Estrada GCF. TEMA 7-2015: micro ARN y enfermedad pulmonar obstructiva crónica. Rev Clínica Esc Med UCR-HSJD. 2015;5(2):65-70. doi: 10.15517/rc_ucr-hsjd.v5i2.18884.

28. Mizuno S, Bogaard HJ, Gomez-Arroyo J, Alhussaini A, Kraskauskas D, Cool CD, et al. MicroRNA-199a-5p is associated with hypoxiainducible factor-1 $\alpha$ expression in lungs from patients with COPD. Chest. 2012;142(3):663-672. doi: 10.1378/chest.11-2746.

29. Du Y, Ding Y, Chen X, Mei Z., Ding H, Wu Y, et al. MicroRNA-181c inhibits cigarette smoke-induced chronic obstructive pulmonary disease by regulating CCN1 expression. Respir Res. 2017;18(1):155. doi: 10.1186/s12931-017-0639-1.

30. Paschalaki KE, Zampetaki A, Baker JR, Birrell MA, Starke RD, Belvisi MG, et al. Downregulation of MicroRNA-126 Augments DNA damage response in cigarette smokers and patients with chronic obstructive pulmonary disease. Am J Respir Crit Care Med. 2018;197(5):665-668. doi: 10.1164/rccm.201706-1304LE

31. O'Leary L, Sevinc K, Papazoglou IM, Tildy B, Detillieux K, Halayko $\mathrm{JA}$, et al. Airway smooth muscle inflammation is regulated by microRNA-145 in COPD. FEBS Lett. 2016;590(9):1324-1334. doi: 10.1002/1873-3468.12168.

32. Fujita Y, Araya J, Ito S, Kobayashi K, Kosaka N, Yoshioka Y, et al. Suppression of autophagy by extracellular vesicles promotes myofibroblast differentiation in COPD pathogenesis. J Extracell Vesicles. 2015;4(1):1-12. doi: 10.3402/jev.v4.28388

33. Kara M, Kirki G, Kalemci S. Differential expression of microRNAs in chronic obstructive pulmonary disease. Adv Clin Exp Med. 2016;25(1):21-26. doi: 10.17219/acem/28343.

34. Angulo M, Lecuona E, Sznajder Jl. Rol de los microARN en las enfermedades pulmonares. Arch Bronconeumol. 2012;48(9):325-330. doi: 10.1016/j.arbres.2012.04.011.
35. Coronado RE. Therapeutic effect of extracellular vesicles derived from adult/perinatal human mesenchymal stem cells. In: Perinatal stem cells: research and therapy. Elsevier Inc.; 2018:201-215. doi: 10.1016/B978-0-12-812015-6.00015-7.

36. Oglesby IK, Bray IM, Chotirmall SH, Stallings RL, O'Neill SL, McElvaney NG, et al. miR-126 is downregulated in cystic fibrosis airway epithelial cells and regulates TOM1 expression. J Immunol. 2010;184(4):1702-1709. doi: 10.4049/jimmunol.0902669.

37. Barreto-Rodríguez JO, Mejía ME, Buendía-Roldán I. Panorama actual de la fibrosis pulmonar idiopática en México. Neumol Cir Torax. 2015;74(4):256-261. [Accessed February 14, 2021] Disponible en: www.revistanct.org.mx

38. Kuse N, Kamio K, Azuma A, Matsuda K, Inomata M, Usuki J, et al. Exosome-derived microRNA-22 ameliorates pulmonary fibrosis by regulating fibroblast-to-myofibroblast differentiation in vitro and in vivo. J Nippon Med Sch. 2020;87(3):118-128. doi: 10.1272/jnms. JNMS.2020_87-302.

39. Dinh PUC, Paudel D, Brochu H, Popowski KD, Gracieux MC, Cores $\mathrm{J}$, et al. Inhalation of lung spheroid cell secretome and exosomes promotes lung repair in pulmonary fibrosis. Nat Commun. 2020;11(1):114. doi: 10.1038/s41467-020-14344-7.

40. Mora G, Romero A, Maria M. Guía para pacientes con fibrosis pulmonar ideopática. Editorial Respira; 2012.

41. Njock MS, Guiot J, Henket MA, Nivelles O, Thiry M, Dequiedt $\mathrm{F}$, et al. Sputum exosomes: Promising biomarkers for idiopathic pulmonary fibrosis. Thorax. 2018;74(3):309-312. doi: 10.1136/ thoraxjnl-2018-211897.

42. Wright EJ, Momeni A, Kraneburg UM, Otake LR, Echo A, Lee $\mathrm{T}$, et al. Clinical significance of internal mammary lymph node biopsy during microsurgical breast reconstruction: review of 264 cases. Plast Reconstr Surg. 2016;137(6):917e-922e. doi: 10.1097/ PRS. 0000000000002174 .

43. Lino CCL, Henaoui IS, Courcot E, Otake LR, Echo A, Lee T, et al. miR-199a-5p is upregulated during fibrogenic response to tissue injury and mediates TGFbeta-induced lung fibroblast activation by targeting caveolin-1. Scott HS, ed. PLoS Genet. 2013;9(2):e1003291. doi: 10.1371/journal.pgen.1003291.

44. Crespo P. La ruta RAS-ERK como diana antitumoral. Redes señalización y estrategias Ter. Publicado en línea 2009:123-137.

45. Sánchez-López E, Rodrígues-Díez R, Rodríguez-Vita J, RayegoMateos, Rodrígues-Díez RR, Rodríguez García E, et al. Revisiones cortas. El factor de crecimiento de tejido conectivo (CTGF): factor clave en el inicio y la progresión del daño renal. Nefrologia. 2009;29(5):382-391.

46. Liu G, Friggeri A, Yang Y, Milosevic J, Ding Q, Thannickal VJ, et al. miR-21 mediates fibrogenic activation of pulmonary fibroblasts and lung fibrosis. J Exp Med. 2010;207(8):1589-1597. doi: 10.1084/jem.20100035.

47. Yang S, Banerjee S, De Freitas A, Sanders YY, Ding Q, Matalon S, et al. Participation of miR-200 in pulmonary fibrosis. Am J Pathol. 2012;180(2):484-493. doi: 10.1016/j.ajpath.2011.10.005,

48. Kriegel AJ, Liu Y, Fang Y, Ding X, Liang M. The miR-29 family: Genomics, cell biology, and relevance to renal and cardiovascular injury. Physiol Genomics. 2012;44(4):237-244. doi: 10.1152/ physiolgenomics.00141.2011,

49. Pottier N, Maurin T, Chevalier B, Puisségur MP, Lebrigand K, RobbeSermesant K, et al. Identification of keratinocyte growth factor as a target of microRNA-155 in lung fibroblasts: implication in epithelialmesenchymal interactions. Jin D-Y, ed. PLoS One. 2009;4(8):e6718. doi: 10.1371/journal.pone.0006718. 
50. Li H, Zhao X, Shan H, Liang H. MicroRNAs in idiopathic pulmonary fibrosis: involvement in pathogenesis and potential use in diagnosis and therapeutics. Acta Pharm Sin B. 2016;6(6):531-539. doi: 10.1016/j. apsb.2016.06.010.

51. Ridge C, McErlean AM, Ginsberg MS. Epidemiology of lung cancer. Semin Intervent Radiol. 2013;30(2):93-98. doi: 10.1055/s-00331342949.

52. Aldaco-Sarvide F, Pérez-Pérez P, Cervantes-Sánchez G, TorrecillasTorres L, Erazo-Valle-Solís AA, Cabrera-Galeana P, et al. Mortality from cancer in Mexico: 2015 update. Gac Mex Oncol. 2019;17(1). doi: 10.24875/j.gamo.m18000158.

53. Medina Morales F, Salazar Flores M, García-Sancho MC, Franco MF. Epidemiología descriptiva del cáncer pulmonar en el Instituto Nacional de Enfermedades Respiratorias, México, 1997-2000. Rev Inst Nac Enferm Respir. 2002;15(3):149-152.

54. Vinaccia S, Quiceno J, Fernández H, Contreras F, Bedoya B, Tobón $\mathrm{S}$, et al. Calidad de vida, personalidad resistente y apoyo social percibido en pacientes con diagnóstico de cáncer pulmonar. Psicol y Salud. 2014;15(2):207-220.

55. Chen Z, Zeng H, Guo Y, Liu P, Pan H, Deng A, et al. MiRNA-145 inhibits non-small cell lung cancer cell proliferation by targeting c-Myc. J Exp Clin Cancer Res. 2010;29(1):151. doi: 10.1186/1756-9966-29-151.

56. Herbst RS, Morgensztern D, Boshoff $C$. The biology and management of non-small cell lung cancer. Nature. 2018;553(7689):446-454. doi: 10.1038/nature25183.

57. Rivas-Perez H, Nana-Sinkam P. Integrating pulmonary rehabilitation into the multidisciplinary management of lung cancer: A review. Respir Med. 2015;109(4):437-442. doi: 10.1016/j.rmed.2015.01.001.

58. Kahlert C, Kalluri R. Exosomes in tumor microenvironment influence cancer progression and metastasis. J Mol Med. 2013;91(4):431-437. doi: 10.1007/s00109-013-1020-6.

59. Chow A, Zhou W, Liu L, Fong MY, Champer J, Van Haute D, et al. Macrophage immunomodulation by breast cancer-derived exosomes requires Toll-like receptor 2-mediated activation of NF-кB. Sci Rep. 2014:4:5750. doi: 10.1038/srep05750.

60. Raimondo S, Saieva L, Corrado C, Fontana S, Flugy A, Rizzo A, et al. Chronic myeloid leukemia-derived exosomes promote tumor growth through an autocrine mechanism. Cell Commun Signal. 2015;13(1). doi: 10.1186/s12964-015-0086-x

61. Costa-Silva B, Aiello NM, Ocean AJ, Singh S, Zhang H, Thakur $\mathrm{BK}$, et al. Pancreatic cancer exosomes initiate pre-metastatic niche formation in the liver. Nat Cell Biol. 2015;17(6):816-826. doi: 10.1038/ ncb3169.

62. Safaei R, Larson BJ, Cheng TC, Gibson MA, Otani S, Naerdemann $\mathrm{W}$, et al. Abnormal lysosomal trafficking and enhanced exosomal export of cisplatin in drug-resistant human ovarian carcinoma cells. Mol Cancer Ther. 2005;4(10):1595-1604. doi: 10.1158/1535-7163. MCT-05-0102.

63. Farazi TA, Spitzer Jl, Morozov P, Tuschl T. MiRNAs in human cancer. J Pathol. 2011;223(2):102-115. doi: 10.1002/path.2806.

64. Yanaihara N, Caplen N, Bowman E, Seike M, Kumamoto K, Yi M, et al. Unique microRNA molecular profiles in lung cancer diagnosis and prognosis. Cancer Cell. 2006;9(3):189-198. doi: 10.1016/j. ccr.2006.01.025

65. Rabinowits G, Gerçel-Taylor C, Day JM, Taylor DD, Kloecker GH. Exosomal microRNA: A diagnostic marker for lung cancer. Clin Lung Cancer. 2009;10(1):42-46. doi: 10.3816/CLC.2009.n.006.

66. Liu Q, Yu Z, Yuan S, Xie W, Li C, Hu Z, et al. Circulating exosomal microRNAs as prognostic biomarkers for non-small-cell lung cancer. Oncotarget. 2017;8(8):13048-13058. doi: 10.18632/ oncotarget.14369.

67. Yuan D, Xu J, Wang J, Pan Y, Fu J, Bai Y, et al. Extracellular miR-1246 promotes lung cancer cell proliferation and enhances radioresistance by directly targeting DR5. Oncotarget. 2016;7(22):32707-32722. doi: 10.18632/oncotarget.9017.

68. Jin X, Chen Y, Chen H, Fei S, Chen D, Cai X, et al. Evaluation of tumorderived exosomal miRNA as potential diagnostic biomarkers for earlystage non-small cell lung cancer using next-generation sequencing. Clin Cancer Res. 2017;23(17):5311-5319. doi: 10.1158/1078-0432. CCR-17-0577.

69. Organización Mundial de la Salud. Influenza (Seasonal). Published November 2018. [Accessed February 15, 2021] Available in: https:// www.who.int/news-room/fact-sheets/detail/influenza-(seasonal)

70. Centro de Control de Enfermedades. Outbreak of Swine-Origin Influenza A (H1N1) Virus Infection --- Mexico, March--April 2009. Publicado en Mayo 2009. [Accesado Febrero 15, 2021. https://www. cdc.gov/mmwr/preview/mmwrhtml/mm5817a5.htm

71. Luo M. Influenza virus entry. Adv Exp Med Biol. 2012;726:201-221. doi: 10.1007/978-1-4614-0980-9_9.

72. Gutiérrez-Salinas J, Mondragón-Terán P, García-Ortíz L, HernándezRodríguez S, Romero-Domínguez E, Ramírez-García S, et al. Virus de la influenza humana como ejemplo de enfermedad emergente en México. Med Interna Mex. 2016;32(2):213-224.

73. Testa JS, Apcher GS, Comber JD, Eisenlohr LC. Exosome-driven antigen transfer for MHC class II presentation facilitated by the receptor binding activity of influenza hemagglutinin. J Immunol. 2010;185(11):6608-6616. doi: 10.4049/jimmunol.1001768.

74. Bedford JG, Infusini G, Dagley LF, Villalon-Letelier F, Zheng MZ , Bennett-Wood V, et al. Airway exosomes released during influenza virus infection serve as a key component of the antiviral innate immune response. Front Immunol. 2020;11:1-14. doi: 10.3389/ fimmu.2020.00887.

75. Maemura T, Fukuyama S, Kawaoka Y. High Levels of miR-483-3p are present in serum exosomes upon infection of mice with highly pathogenic avian influenza virus. Front Microbiol. 2020;11:1-8. doi: 10.3389/fmicb.2020.00144.

76. Zhang F, Sun X, Zhu Y, Qin W. Downregulation of miR-146a inhibits influenza $A$ virus replication by enhancing the type I interferon response in vitro and in vivo. Biomed Pharmacother. 2019;111:740750. doi: 10.1016/j.biopha.2018.12.103.

77. Gui S, Chen X, Zhang M, Zhao F, Wan Y, Wang L, et al. Mir-302C mediates influenza $A$ virus-induced IFN $\beta$ expression by targeting NF-кB inducing kinase. FEBS Lett. 2015;589(24PartB):4112-4118. doi: 10.1016/j.febslet.2015.11.011.

78. Peng S, Wang J, Wei S, Li C, Zhou K, Hu J, et al. Endogenous Cellular MicroRNAs mediate antiviral defense against influenza a virus. Mol Ther-Nucleic Acids. 2018;10:361-375. doi: 10.1016/j.omtn.2017.12.016.

79. Walls AC, Park YJ, Tortorici MA, Wall A, McGuire AT, Veesler D. Structure, function, and antigenicity of the SARS-CoV-2 spike glycoprotein. Cell. 2020;181(2):281-292.e6. doi: 10.1016/j. cell.2020.02.058

80. Hu B, Guo H, Zhou P, Shi ZL. Characteristics of SARS-CoV-2 and COVID-19. Nat Rev Microbiol. 2021;19:141-154. doi: 10.1038/s41579020-00459-7.

81. Zhou P, Yang X Lou, Wang XG, Hu B, Zhang L, Zhang W, et al. A pneumonia outbreak associated with a new coronavirus of probable bat origin. Nature. 2020;579(7798):270-273. doi: 10.1038/s41586020-2012-7. 
82. Huang C, Wang Y, Li X, Ren L, Zhao J, Hu Y, et al. Clinical features of patients infected with 2019 novel coronavirus in Wuhan, China. Lancet. 2020;395(10223):497-506. doi: 10.1016/S0140-6736(20)30183-5.

83. Zhang W, Zhao Y, Zhang F, Wanga Q, Li T, Liu Z, et al. The use of anti-inflammatory drugs in the treatment of people with severe coronavirus disease 2019 (COVID-19): the experience of clinical immunologists from China. Clin Immunol. 2020;214:108393. doi: 10.1016/j.clim.2020.108393.

84. Shah VK, Firmal P, Alam A, Ganguly D, Chattopadhyay S. Overview of immune response during SARS-CoV-2 infection: lessons from the past. Front Immunol. 2020;11:1949. doi: 10.3389/fimmu.2020.01949.

85. Heininger U. Severe acute respiratory syndrome coronavirus 2 vaccines: Setting expectations appropriately. Pediatr Infect Dis J. 2020;39(7):e123-e124. doi: 10.1097/INF.0000000000002741.

86. Hassanpour M, Rezaie J, Nouri M, Panahi Y. The role of extracellular vesicles in COVID-19 virus infection. Infect Genet Evol. 2020;85:104422. doi: 10.1016/j.meegid.2020.104422.

87. Giannessi F, Aiello A, Franchi F, Percario ZA, Affabris E. The role of extracellular vesicles as allies of HIV, HCV and SARS viruses. Viruses. 2020;12(5):571. doi: 10.3390/v12050571.

88. Khan MAAK, Sany MRU, Islam MS, Islam ABMMK. Epigenetic regulator miRNA pattern differences among SARS-CoV, SARSCoV-2, and SARS-CoV-2 world-wide isolates delineated the mystery behind the epic pathogenicity and distinct clinical characteristics of pandemic COVID-19. Front Genet. 2020;11:765. doi: 10.3389/ fgene.2020.00765.

89. Sengupta V, Sengupta S, Lazo A, Woods P, Nolan A, Bremer N. Exosomes derived from bone marrow mesenchymal stem cells as treatment for severe COVID-19. Stem Cells Dev. 2020;29(12):747-754. doi: 10.1089/scd.2020.0080.

90. Bertolazzi G, Cipollina C, Benos P V., Tumminello M, Coronnello C. miR-1207-5p can contribute to dysregulation of inflammatory response in COVID-19 via targeting SARS-CoV-2 RNA. Front Cell Infect Microbiol. 2020;10:1-8. doi: 10.3389/fcimb.2020.586592.

91. Lu D, Chatterjee S, Xiao K, Riedel I, Wang Y, Foo R, et al. MicroRNAs targeting the SARS-CoV-2 entry receptor ACE2 in cardiomyocytes. J Mol Cell Cardiol. 2020;148:46-49. doi: 10.1016/j. yjmcc.2020.08.017.

92. Khalaj K, Figueira RL, Antounians L, Lauriti G, Zani A. Systematic review of extracellular vesicle-based treatments for lung injury: are EVs a potential therapy for COVID-19? J Extracell Vesicles. 2020;9(1):1795365. doi: 10.1080/20013078.2020.1795365.

93. Organización Mundial de la Salud. Pneumonia. Publicado en Agosto 2019. [Accesado Febrero 15, 2021]. https://www.who.int/news-room/ fact-sheets/detail/pneumonia

94. Instituto Nacional de Salud Pública. ¡El invierno se acerca! Y la neumonía lo sabe. Publicado 2020. Accesado Febrero 15, 2021]. Disponible en: https://www.insp.mx/avisos/5121-dia-mundialneumonia-invierno.html

95. Forum of International Respiratory Societies. The Global Impact of Respiratory Disease. Second.; 2017.

96. Carroll KC, Adams LL. Lower respiratory tract infections. Microbiol Spectr. 2016;4(4). doi: 10.1128/microbiolspec.DMIH2-0029-2016.

97. Periselneris JN, Brown JS, José RJ. Pneumonia. Med (United Kingdom). 2020;48(6):351-355. doi: 10.1016/j.mpmed.2020.03.002.

98. Cilloniz C, Martin-Loeches I, Garcia-Vidal C, Jose AS, Torres A. Microbial etiology of pneumonia: Epidemiology, diagnosis and resistance patterns. Int J Mol Sci. 2016;17(12):2120. doi: 10.3390/ ijms17122120.
99. Kovach MA, Singer BH, Newstead MW, Zeng X, Moore TA, White $\mathrm{ES}$, et al. IL-36y is secreted in microparticles and exosomes by lung macrophages in response to bacteria and bacterial components. $J$ Leukoc Biol. 2016;100(2):413-421. doi: 10.1189/jlb.4A0315-087R.

100. Chahar HS, Corsello T, Kudlicki AS, Komaravelli N, Casola A. Respiratory syncytial virus infection changes cargo composition of exosome released from airway epithelial cells. Sci Rep. 2018;8(1). doi: 10.1038/s41598-017-18672-5.

101. Wu X, Wu C, Gu W, Ji H, Zhu L. Serum exosomal microRNAs predict acute respiratory distress syndrome events in patients with severe community-acquired pneumonia. Biomed Res Int. 2019;2019. doi: 10.1155/2019/3612020.

102. Fish JE, Santoro MM, Morton SU, Yu S, Yeh RF, Wythe JD, et al. miR-126 regulates angiogenic signaling and vascular integrity. Dev Cell. 2008;15(2):272-284. doi: 10.1016/j.devcel.2008.07.008.

103. Du W, Zhang K, Zhang S, Wang R, Nie Y, Tao H, et al. Enhanced proangiogenic potential of mesenchymal stem cell-derived exosomes stimulated by a nitric oxide releasing polymer. Biomaterials. 2017;133:70-81. doi: 10.1016/j.biomaterials.2017.04.030.

104. Jansen F, Yang X, Hoelscher M, Cattelan A, Schmitz T, Proebsting $\mathrm{S}$, et al. Endothelial microparticle-mediated transfer of microRNA-126 promotes vascular endothelial cell repair via spred1 and is abrogated in glucose-damaged endothelial microparticles. Circulation. 2013;128(18):2026-2038. doi: 10.1161/CIRCULATIONAHA.113.001720.

105. Huang F, Bai J, Zhang J, Yang D, Fan H, Huang L, et al. Identification of potential diagnostic biomarkers for pneumonia caused by adenovirus infection in children by screening serum exosomal microRNAs. Mol Med Rep. 2019;49(5):4306-4314. doi: 10.3892/mmr.2019.10107.

106. Dernowsek JA, Pereira MC, Fornari TA, Macedo C, Assis AF, Donate $\mathrm{PB}$, et al. Posttranscriptional interaction between miR-450a-5p and miR-28-5p and STAT1 mRNA triggers osteoblastic differentiation of human mesenchymal stem cells. J Cell Biochem. 2017;118(11):40454062. doi: 10.1002/jcb.26060.

107. Dong G, Fan H, Yang Y, Zhao G, You M, Wang T, et al. 17ß-Estradiol enhances the activation of IFN- $\alpha$ signaling in $B$ cells by down-regulating the expression of let-7e-5p, miR-98-5p and miR-145a-5p that target IKKe. Biochim Biophys Acta-Mol Basis Dis. 2015;1852(8):1585-1598. doi: 10.1016/j.bbadis.2015.04.019.

108. Pacholewska A, Kraft M, Gerber V, Jagannathan V. Differential expression of serum microRNAs supports CD4+ T cell differentiation into Th2/Th17 cells in severe equine asthma. Genes (Basel). 2017;8(12):383. doi: 10.3390/genes8120383.

109. World Health Organization. Global Tuberculosis Report 2020.; 2020. Accessed February 15, 2021. http://apps.who.int/bookorders.

110. Instituto Nacional de Salud Pública. Tuberculosis: la enfermedad infecciosa más mortífera en el mundo. Publicado 2020. [Accesado Febrero 15, 2021]. https://www.insp.mx/avisos/5302-tuberculosisenfermedad-infecciosa-mortifera.html

111. Koch A, Mizrahi V. Mycobacterium tuberculosis. Trends Microbiol. 2018;26(6):555-556. doi: 10.1016/j.tim.2018.02.012.

112. Pai M, Behr MA, Dowdy D, Dheda K, Divangahi M, Boehme CC, et al. Tuberculosis. Nat Rev Dis Prim. 2016;2(1):1-23. doi: 10.1038/nrdp.2016.76.

113. Ernst JD. The immunological life cycle of tuberculosis. Nat Rev Immunol. 2012;12(8):581-591. doi: 10.1038/nri3259.

114. Furin J, Cox H, Pai M. tuberculosis. Lancet. 2019;393(10181):16421656. doi: 10.1016/S0140-6736(19)30308-3.

115. Hadifar S, Fateh A, Yousefi MH, Siadat SD, Vaziri F. Exosomes in tuberculosis: still terra incognita? J Cell Physiol. 2019;234(3):21042111. doi: $10.1002 / j c p .27555$. 
116. Diaz G, Wolfe LM, Kruh-Garcia NA, Dobos KM. Changes in the membrane-associated proteins of exosomes released from human macrophages after Mycobacterium tuberculosis Infection. Sci Rep. 2016;6(1):1-10. doi: 10.1038/srep37975.

117. Kruh-Garcia NA, Wolfe LM, Dobos KM. Deciphering the role of exosomes in tuberculosis. Tuberculosis. 2015;95(1):26-30. doi: 10.1016/j.tube.2014.10.010.

118. Alipoor SD, Tabarsi P, Varahram M, Movassaghi M, Dizaji MK, Folkerts $\mathrm{G}$, et al. Serum exosomal miRNAs are associated with active pulmonary tuberculosis. Dis Markers. 2019;2019. doi: 10.1155/2019/1907426.

119. Lyu L, Zhang X, Li C, Yang T, Wang J, Pan L, et al. Small RNA profiles of serum exosomes derived from individuals with latent and active tuberculosis. Front Microbiol. 2019;10:1174. doi: 10.3389/ fmicb.2019.01174.

120. LiY, Yin Z, Fan J, Zhang S, Yang W. The roles of exosomal mirnas and Incrnas in lung diseases. Signal Transduct Target Ther. 2019;4(1):1-12. doi: 10.1038/s41392-019-0080-7.

121. Wang K, Long B, Jiao JQ, Wang JX, Liu JP, Li Q, et al. MiR-484 regulates mitochondrial network through targeting Fis1. Nat Commun. 2012;3. doi: 10.1038/ncomms1770.

122. Hu X, Liao S, Bai H, Wu L, Wang M, Wu Q, et al. Integrating exosomal microRNAs and electronic health data improved tuberculosis diagnosis. EBioMedicine. 2019;40:564-573. doi: 10.1016/j. ebiom.2019.01.023.

123. Papageorgiou SG, Kontos CK, Tsiakanikas P, Stavroulaki G, Bouchla $A$, Vasilatou D, et al. Elevated miR-20b-5p expression in peripheral blood mononuclear cells: A novel, independent molecular biomarker of favorable prognosis in chronic lymphocytic leukemia. Leuk Res. 2018;70:1-7. doi: 10.1016/j.leukres.2018.04.014.

124. Nagpal N, Kulshreshtha R. miR-191: an emerging player in disease biology. Front Genet. 2014;5:99. doi: 10.3389/fgene.2014.00099.

125. Fu Y, Yi Z, Wu X, Li J, Xu F. Circulating microRNAs in patients with active pulmonary tuberculosis. J Clin Microbiol. 2011;49(12):42464251. doi: 10.1128/JCM.05459-11.
126. Sharbati J, Lewin A, Kutz-Lohroff B, Kamal E, Einspanier R, Sharbati S. Integrated MicroRNA-mRNA-analysis of human monocyte derived macrophages upon Mycobacterium avium subsp. hominissuis infection. PLoS One. 2011;6(5):e20258. doi: 10.1371/journal. pone.0020258.

127. Bettencourt P, Marion S, Pires D, Santos LF, Lastrucci C, Carmo N, et al. Actin-binding protein regulation by microRNAs as a novel microbial strategy to modulate phagocytosis by host cells: the case of N-Wasp and miR-142-3p. Front Cell Infect Microbiol. 2013;3:19. doi: 10.3389/ fcimb.2013.00019.

128. Guo L, Zhou L, Gao Q, Zhang A, Wei J, Hong D, et al. MicroRNA144-3p inhibits autophagy activation and enhances Bacillus Calmette-Guérin infection by targeting ATG4a in RAW264.7 macrophage cells. PLoS One. 2017;12(6):e0179772. doi: 10.1371/ journal.pone.0179772.

129. Gu X, Gao Y, Mu DG, Fu EQ. MiR-23a-5p modulates mycobacterial survival and autophagy during Mycobacterium tuberculosis infection through TLR2/MyD88/NF-kB pathway by targeting TLR2. Exp Cell Res. 2017;354(2):71-77. doi: 10.1016/j.yexcr.2017.03.039.

130. Alipoor SD, Mortaz E, Tabarsi P, Farnia P, Mirsaeidi M, Garssen J, et al. Bovis Bacillus Calmette-Guerin (BCG) infection induces exosomal miRNA release by human macrophages. J TransI Med. 2017;15(1):105. doi: 10.1186/s12967-017-1205-9.

131. Barwari T, Skroblin P, Mayr M. When sweet turns salty glucose-induced suppression of atrial natriuretic peptide by MicroRNA-425. J Am Coll Cardiol. 2016;67(7):813-816. doi: 10.1016/j.jacc.2015.12.008.

132. Smith VL, Cheng Y, Bryant BR, Schorey JS. Exosomes function in antigen presentation during an in vivo Mycobacterium tuberculosis infection. Sci Rep. 2017;7. doi: 10.1038/srep43578.

Conflicto de intereses: Los autores declaran no tener conflicto de intereses. 